\title{
ANÁLISE DO DESEMPENHO TÉRMICO DE HABITAÇÃO DE INTERESSE SOCIAL COM PAREDES DE CONCRETO EM UBERLÂNDIA-MG
}

\author{
ANAL YSIS OF THE THERMAL PERFORMANCE OF SOCIAL HOUSING WITH CONCRETE \\ WALLS IN UBERLÂNDIA-MG
}

\author{
Doberta Bastos de Oliveira ${ }^{1}$ \\ Camila dos Reis Alves ${ }^{2}$ \\ ${ }^{1}$ Universidade de Brasília, Brasília, DF, \\ Brasil, robertab.o@hotmail.com \\ 2 Universidade Federal de Uberlândia, \\ Uberlândia, MG, Brasil, \\ camiladralves@gmail.com
}

\author{
Contribuição dos autores: \\ RBO: conceituação, curadoria de dados, \\ análise formal, metodologia, \\ administração de projetos, programas, \\ supervisão, validação, visualização, escrita \\ - rascunho original, escrita - revisão e \\ edição. CRA: conceituaçãao, curadoria de \\ dados, análise formal, investigação, \\ metodologia, administração de projetos, \\ supervisão, validação, visualização, escrita \\ - rascunho original, escrita - revisão e \\ edição.
}

Fomento: Coordenação de Aperfeiçoamento de Pessoal de Nível Superior

Declaração de conflito: nada foi declarado.

Editor Responsável:

Guilherme Aris Parsekian (D)

\begin{abstract}
Resumo
O sistema construtivo de paredes de concreto tem sido amplamente utilizado na construção de habitações de interesse social (HIS). No entanto, questões relacionadas ao desempenho térmico necessitam de maiores estudos e atenção. Neste contexto, tem-se a avaliação do desempenho térmico segundo a ABNT NBR 15575:2013 de uma HIS construída com paredes de concreto moldado in loco na cidade de Uberlândia-MG. Inicialmente foi utilizado o método simplificado para avaliação do projeto real para a determinação do nível de desempenho térmico. Em seguida, foram simulados 6 cenários para o verão e para o inverno, de acordo com a orientação solar mais crítica. Para as análises, utilizou-se o software Energy Plus com as 8760 horas do ano. Trata-se de uma comparação entre os resultados obtidos e os requisitos normativos que preveem a comparação das temperaturas internas com as externas, bem como as internas com as temperaturas do dia típico. Como resultados, a HIS não atingiu os níveis mínimos para o método simplificado. Para as simulações, tem-se diversas análises comparativas quanto ao aumento ou redução das temperaturas internas nas zonas térmicas da edificação. $O$ projeto real com beiral e paredes externas na cor clara atingiu o nível de desempenho térmico mínimo para o verão e para o inverno, no entanto, outras análises foram incorporadas possibilitando ponderações importantes. Faz-se uma crítica também quanto aos critérios normativos para desempenho térmico que destoaram entre si e à qualidade dos projetos que têm sido replicados na cidade sem uma preocupação com o usuário.
\end{abstract}

Palavras-chave: Desempenho térmico. Paredes de concreto moldadas in loco. Habitação de interesse social.

\begin{abstract}
The concrete wall construction system has been widely used in the construction of social housing (HIS). However, issues related to the thermal performance of this system need further study and attention. In this context, there is the evaluation of thermal performance according to ABNT NBR 15575: 2013 of a HIS built with concrete walls molded in loco in Uberlândia-MG. Initially, the simplified method for the real project was used to determine the level of thermal performance. Then, six scenarios were simulated for summer and winter, according to the most critical solar orientation. For the analyzes, the Energy Plus software was used for 8760 hours of the year. It is a comparison between the results obtained and the normative requirements that provide for the comparison of internal and external temperatures and internal temperatures with the temperatures of the typical day. As a result, HIS did not achieve the minimum levels for the simplified method. For the simulations, several comparatives analyze the increase or reduction of internal temperatures in the building's thermal zones. The real project with eaves and external painting in light color reached the minimum thermal performance level for summer and winter; however, other analyzes were incorporated, allowing important considerations. Criticism is also made on normative criteria for inconsistent thermal performance and the quality of design replicated in the city without concern for the user.
\end{abstract}

Keywords: Thermal performance. Concrete walls molded in loco. Social housing.

How to cite this article:

OLIVEIRA, R. B. de; ALVES, C. dos R. Análise do desempenho térmico de habitação de interesse social com paredes de concreto em Uberlândia-MG. PARC Pesquisa em Arquitetura e Construção, Campinas, SP, v. 12, p. e021006, 2021. DOI: http://dx.doi.org/10.20396/parc.v12i00.8661094 


\section{Introdução}

A produção de empreendimentos com muitas unidades impulsionada pelo Programa Minha Casa Minha Vida (PMCMV) em 2009, possibilitou que técnicas construtivas que necessitam de produção seriada em grande escala fossem utilizadas. Neste contexto, o sistema construtivo de paredes de concreto moldadas in loco está cada vez mais presente na construção civil. Dados apontam que este sistema tem prevalecido no PMCMV, e no segundo semestre de 2015 este percentual já chegava a 52\% (SANTOS, 2016). Em Uberlândia-MG cerca de $63 \%$ das unidades habitacionais (UH) inseridas na faixa 1 utilizaram paredes de concreto. No município de Uberlândia-MG das 11.650 UH construídas por meio de empreendimentos faixa 1 do PMCMV, 7.376 utilizaram o sistema construtivo de paredes de concreto, representando cerca de $63 \%$ das UH, sendo 2.176 apartamentos em empreendimentos multifamiliares verticais e 5.200 casas em empreendimentos unifamiliares horizontais (ALVES, 2020).

Diante disso, é importante avaliar qual o impacto da implementação deste sistema construtivo no desempenho térmico de edificações, especialmente de habitações de interesse social (HIS). Oliveira et al. (2014) e Rotta (2009) chamam a atenção para a produção seriada de uma mesma tipologia construtiva sendo empregada em todo Brasil, muitas vezes com baixa qualidade construtiva e desconsiderando as diversas condições climáticas, tecnológicas, culturais e socioeconômicas do território.

Nesse sentido, estudos relacionados ao desempenho térmico de edificações construídas em parede de concreto apontam que há necessidade de modificações para atender às recomendações mínimas. Ferreira e Pereira (2012) avaliaram o desempenho térmico de HIS e observaram que o uso de sistemas construtivos em concreto não é adequado para as zonas bioclimáticas (ZBs) 7 e 8 , e que na condição de verão o desempenho das paredes de concreto foi apenas mínimo nas demais ZBs.

Uma análise do desempenho térmico de envoltórias em concreto para as oito ZBs, realizada por Oliveira et al. (2015), levou em consideração as recomendações da NBR 15220:2005 e NBR 15575:2013, além do Regulamento Técnico da Qualidade para o Nível de Eficiência Energética de Edificações Residenciais (RTQ-R) e da certificação Selo Casa Azul. Todas as prescrições apontaram para a necessidade de isolamento térmico nas paredes de concreto. Além disso, verificou-se falta de uniformização na legislação brasileira, uma vez que os valores indicados são distintos.

Por outro lado, Lorenzi e Silva Filho (2015) analisaram o desempenho de paredes de concreto armado, pelo método de medição na NBR 15575:2013 em um protótipo de escala real de uma HIS inserida na ZB 3. Verificaram que o protótipo é compatível com os limites normativos, para as condições de dia típico tanto para verão como inverno.

Outra questão bastante discutida, é a que o método de simulação da NBR 15575:2013 pode produzir resultados que não representam o desconforto térmico dos usuários. Alguns autores têm apresentado questionamentos com relação as fronteiras consideradas para o dia típico (SORGATO et al., 2012; FERREIRA; PEREIRA, 2012; SILVA et al., 2014; SORGATO; MELO; LAMBERTS, 2013; SOARES; SILVA, 2013; ZANONI; SANCHEZ; BAUER, 2017; OLIVEIRA; SALOMÃO, 2018; OLIVEIRA; ALVES, 2019; GUARDA; DURANTE; CALLEJAS, 2020).

Neste contexto, este trabalho visa colaborar com esta discussão e apresenta uma comparação de resultados obtidos com o método simplificado e de simulação do desempenho térmico, com os requisitos existentes para avaliação segundo a NBR15575 (ABNT, 2013a, 2013b, 2013c), com base em um estudo de caso de um projeto real de HIS do PMCMV na cidade de Uberlândia-MG. 


\section{Materiais e método}

Para avaliação do desempenho térmico, foi selecionado como objeto de estudo um projeto real de HIS, implantada em Uberlândia/MG na zona oeste da cidade. Aplicou-se os métodos de avaliação simplificado e simulações computacionais de cenários prédeterminados por meio do software EnergyPlus com o auxílio do plug-in Euclid. Apesar do advento do processo BIM nas modelagens energéticas, estudos como o de Queiróz, Grigoletti e Santos (2019), alertam que existem problemas de interoperabilidade que podem interferir significativamente nas análises, e por isso recomendam a utilização desse plug-in.

Neste contexto, para a aplicação dos métodos apresentados a seguir, foram levantadas a planta baixa arquitetônica da edificação e apropriação de dados necessários para as avaliações. Por fim, com as simulações realizadas, analisou-se os resultados apresentados por meio de tabelas, quadros e gráficos, comparando-os com os requisitos da NBR 15575:2013: comparação do dia típico com as temperaturas internas, e das temperaturas externas com as internas para os períodos de verão e inverno.

\section{Caracterização do objeto de estudo}

A UH conta com uma área total de $45 \mathrm{~m}^{2}$; pé-direito de 2,60 m; fundação do tipo radier; laje maciça; cobertura sobre estrutura metálica, com telha de concreto de espessura $12 \mathrm{~mm}$ e beiral de $50 \mathrm{~cm}$; janelas de vidro liso comum com $6 \mathrm{~mm}$ de espessura; duas portas externas de alumínio e uma de correr de vidro liso temperado com $10 \mathrm{~mm}$ de espessura; portas internas de madeira. Para este estudo, foi admitida pintura externa na cor branca, conforme indicado no projeto arquitetônico. A Figura 1 mostra a planta baixa real da HIS e a divisão dos ambientes em 4 zonas térmicas conforme recomendado pela NBR 15575-1 (2013a). A Tabela 1 apresenta um resumo das propriedades termofísicas dos materiais construtivos extraídas da NBR 15220 (ABNT, 2005).

A cidade de Uberlândia-MG, localizada na região sudeste do país, possui clima tropical de altitude e pertence à ZB4. Uma análise baseada no seu arquivo climático, obtido da estação meteorológica da cidade, indica que a maior incidência de irradiância ocorre para a orientação Norte, seguida pelas orientações Oeste, Leste e Sul. Em relação a intensidade da chuva dirigida esta mesma sequência é observada.

\section{Avaliação do desempenho térmico pelo método simplificado}

A NBR15575 (ABNT, 2013b, 2013C) apresenta como um dos procedimentos para avaliação térmica das habitações o método simplificado. Sendo assim, para a avaliação dos sistemas de vedações verticais externas (SVVE) são apresentados dois requisitos: adequação de paredes externas e aberturas para ventilação. No caso da cobertura, o requisito é a isolação térmica do componente.

Em relação aos SVVEs, para a ZB4 à qual pertence a cidade de Uberlândia, aplicam-se os critérios da transmitância $(U)$ e capacidade térmicas $(C T)$ que proporcionem o desempenho mínimo, em que a $U$ deve ser de até $3,7 \mathrm{~W} / \mathrm{m} 2 . \mathrm{K}$, considerando que as paredes receberam pintura externa na cor branca e tem absortância ( $\alpha$ ) de 0,20; e a CT deve ser maior que $130 \mathrm{~kJ} / \mathrm{m}^{2} . \mathrm{K}$. Além disso, a relação entre área efetiva de abertura de ventilação e a área do piso deve ser maior ou igual a $7 \%$ em ambientes de permanência prolongada (APP) como salas, cozinhas e dormitórios. Para a cobertura, considerando $\alpha=0,7$ para as telhas de concreto, o valor da $U$ deve ser de no máximo $1,5 \mathrm{~W} / \mathrm{m}^{2} . K$. 
OLIVEIRA, R. B. de; ALVES, C. dos R.

Análise do desempenho térmico de habitação de interesse social com paredes de concreto em Uberlândia-MG

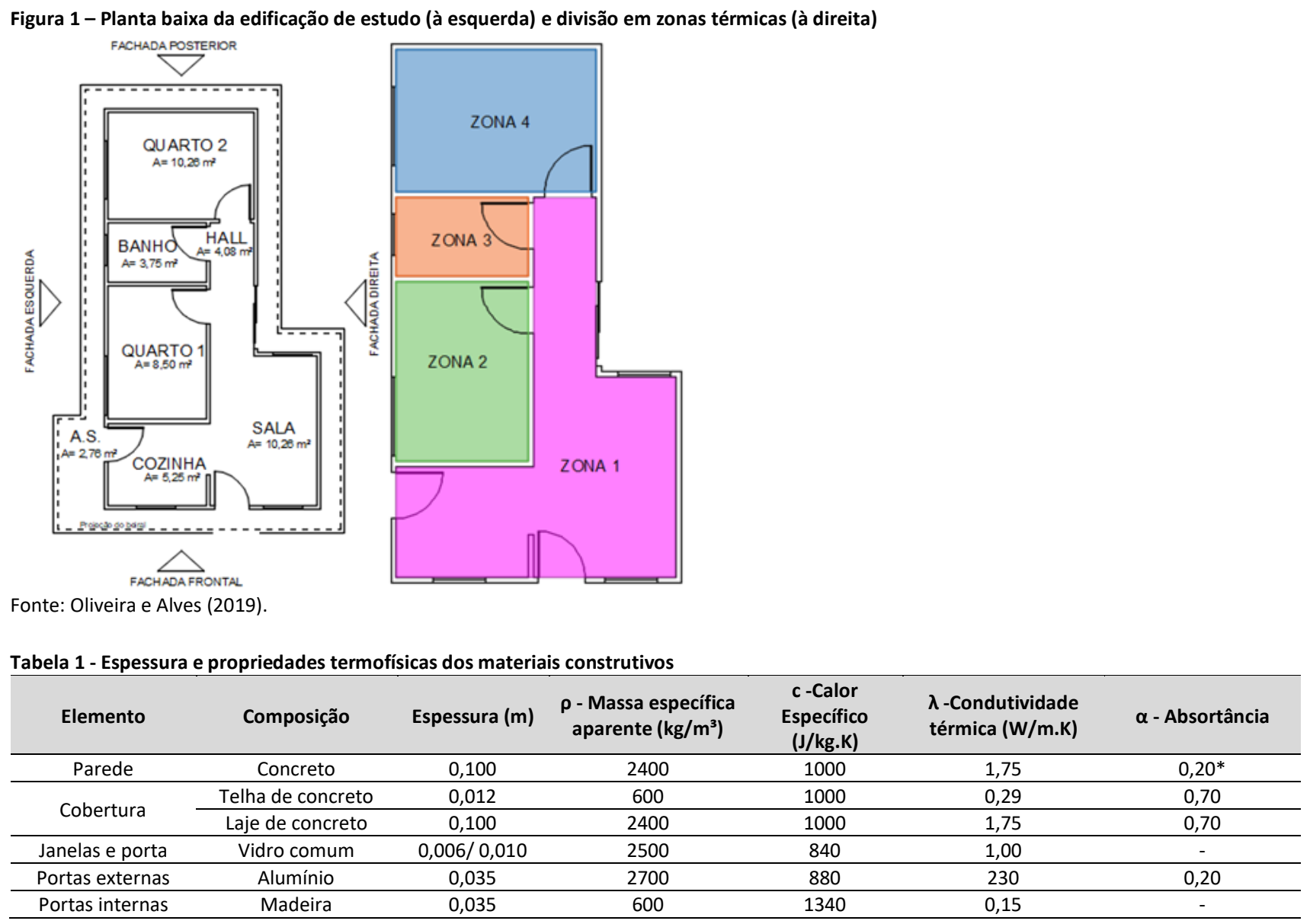

Fonte: as autoras.

A determinação dos valores de transmitância e capacidade térmicas foi realizada conforme procedimentos da NBR 15220 (ABNT,2005), a porcentagem de abertura para ventilação natural foi definida de acordo com PBE EDIFICA (2014).

\section{Avaliação do desempenho térmico pelo método da simulação computacional}

Segundo o procedimento proposto pela NBR15575 (ABNT, 2013a, 2013b) para avaliação do desempenho térmico por simulação computacional são estabelecidos dois requisitos: exigências de desempenho no verão e no inverno. Os critérios aplicados se relacionam aos valores máximos e mínimos de temperatura, por meio de uma comparação entre ambiente externo e o interior da edificação. Os limites para a ZB 4 são apresentados no Quadro 1. Além disso, é permitida a utilização das temperaturas do dia típico. Para a cidade de Uberlândia, a temperatura do dia típico de verão é de $31,2^{\circ} \mathrm{C}$ e $10^{\circ} \mathrm{C}$ para o inverno (ABNT, 2013a), apesar dos questionamentos por parte de vários autores.

Quadro 1 - Critério de avaliação de desempenho térmico para a ZB 4 nas condições de verão e inverno

\begin{tabular}{|c|c|c|}
\hline \multirow{2}{*}{ Nivel de desempenho } & Condições de verão & Condições de inverno \\
\cline { 2 - 3 } & Zonas 1 a 7 & Zonas 1 a 5 \\
\hline $\mathrm{M}$ (mínimo) & $\mathrm{Ti}, \max \leq \mathrm{Te}, \max$ & $\mathrm{Ti}, \mathrm{min} \geq\left(\mathrm{Te}, \mathrm{min}+3^{\circ} \mathrm{C}\right)$ \\
\hline $\mathrm{I}$ (intermediário) & $\mathrm{Ti}, \max \leq\left(\mathrm{Te}, \mathrm{max}-2^{\circ} \mathrm{C}\right)$ & $\mathrm{Ti}, \mathrm{min} \geq\left(\mathrm{Te}, \mathrm{min}+5^{\circ} \mathrm{C}\right)$ \\
\hline $\mathrm{S}$ (superior) & $\mathrm{Ti}, \max \leq\left(\mathrm{Te}, \max -4^{\circ} \mathrm{C}\right)$ & $\mathrm{Ti}, \mathrm{min} \geq\left(\mathrm{Te}, \mathrm{min}+7^{\circ} \mathrm{C}\right)$ \\
\hline
\end{tabular}

Notas: Ti,max é o valor máximo diário da temperatura do ar no interior da edificação, em graus Celsius; Te,max é o valor máximo diário da temperatura do ar exterior à edificação, em graus Celsius; Ti,min é o valor mínimo diário da temperatura do ar no interior da edificação, em graus Celsius; Te,min é o valor mínimo diário da temperatura do ar exterior à edificação, em graus Celsius; Zonas bioclimáticas de acordo com a ABNT NBR 15220-3. Fonte: as autoras. 
Para as simulações computacionais foi utilizado o software EnergyPlus versão 8.7.0. Foram analisadas as 8760 horas correspondentes a um ano, para uma simulação mais próxima da realidade possível, conforme recomendado por SORGATO et al. (2012) e Zanoni (2015). Dessa forma, como os requisitos falam apenas de desempenho no verão e no inverno e não das 4 estações separadamente, fez-se necessário a caracterização dos meses que representam de fato estas estações para Uberlândia-MG, de clima tropical de altitude, semelhante ao da cidade de Brasília-DF. Braga e Amorim (2004) definem dois períodos distintos para esse clima: verão chuvoso de outubro a abril e inverno seco de maio a setembro, possibilitando a simulação para todos os meses do ano. Nesse sentido, foram determinadas as temperaturas máximas e mínimas de cada mês, dentre todas as horas simuladas, para o desempenho do verão e inverno.

A Figura 2 apresenta uma comparação entre as temperaturas médias mensais da superfície de uma fachada em concreto em Uberlândia-MG para as diferentes orientações, em que é possível notar que no verão a orientação Oeste registra as maiores temperaturas mensais. No inverno, as maiores temperaturas ocorrem para Norte na maior parte do tempo. As orientações Sul e Leste registram as menores temperaturas ao longo do ano. Diante disto, considerando que a mesma planta baixa é replicada em diferentes orientações, as simulações foram realizadas para o posicionamento mais crítico, conforme recomenda a NBR 15575 (ABNT, 2013a). Para o verão, a fachada esquerda da UH foi orientada para Oeste e para o inverno, a simulação foi feita com a fachada esquerda orientada para o Sul. Foi utilizado o arquivo climático INMET 2018, taxas de ventilação dos ambientes e cobertura de $1 \mathrm{ren} / \mathrm{h}$, sem a presença de fontes internas de calor, e temperatura do solo de $18^{\circ} \mathrm{C}$.

Figura 2 - Temperatura média mensal por orientação para fachada em concreto

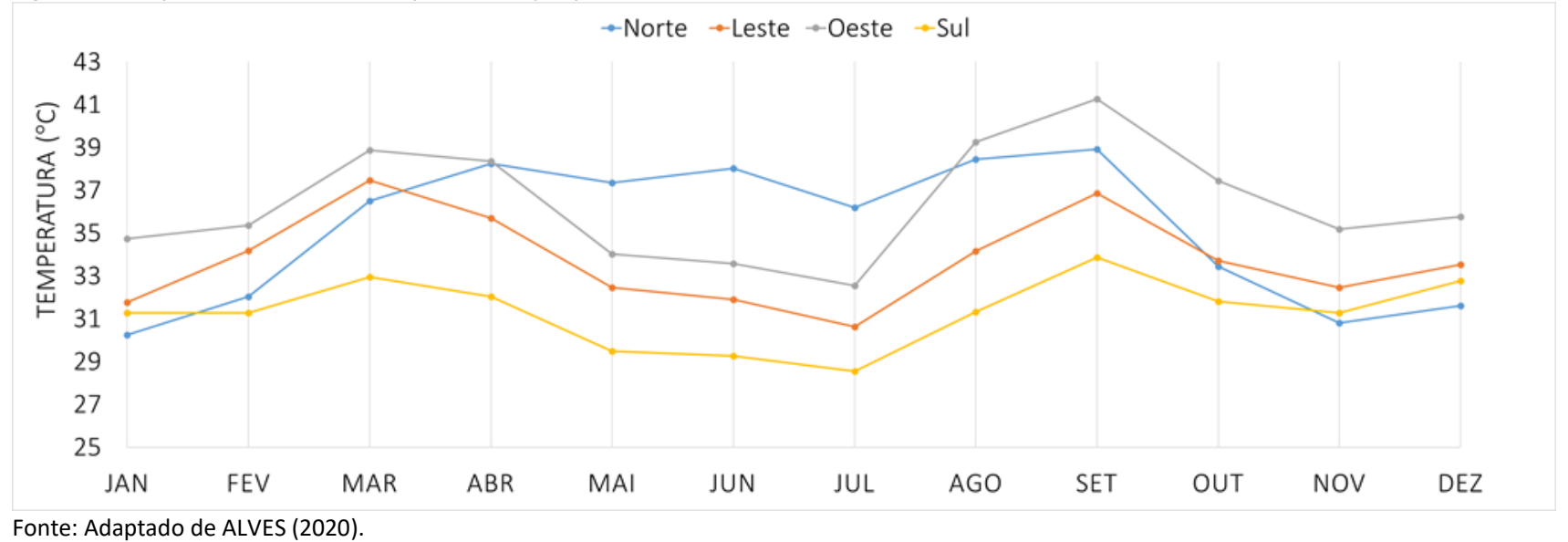

\section{Cenários simulados}

As situações avaliadas nas simulações estão resumidas no Quadro 2. Avaliou-se a influência do beiral e da absortância das paredes externas para as condições reais de projeto. Em seguida, foram simuladas duas possibilidades a fim de verificar o impacto no desempenho térmico da edificação, sendo a cobertura isolada com lã de rocha, e também a substituição da vedação vertical para alvenaria de bloco cerâmico, com dimensão $9 \mathrm{~cm} \times 14 \mathrm{~cm} \times 24 \mathrm{~cm}$ e câmara de ar de $0,175 \mathrm{~m}^{2} . \mathrm{K} / \mathrm{W}$. As demais propriedades termofísicas dos materiais são apresentados na Tabela 2, extraídas da NBR 15220 (ABNT, 2005). 
OLIVEIRA, R. B. de; ALVES, C. dos R.

Análise do desempenho térmico de habitação de interesse social com paredes de concreto em Uberlândia-MG

Quadro 2 - Resumo dos cenários simulados

\begin{tabular}{|c|c|c|}
\hline Projeto real (paredes claras) & Projeto real (paredes escuras) & Beiral + estratégia (paredes claras) \\
\hline com beiral & com beiral & cobertura isolada \\
\hline sem beiral & sem beiral & paredes de alvenaria \\
\hline
\end{tabular}

Fonte: as autoras.

Tabela 2 - Propriedades termofísicas dos materiais constituintes das alternativas simuladas

\begin{tabular}{|c|c|c|c|c|c|}
\hline Elemento & Material & Espessura (m) & $\begin{array}{l}\rho \text { - Massa específica } \\
\text { aparente }\left(\mathrm{kg} / \mathrm{m}^{3}\right)\end{array}$ & $\begin{array}{c}\text { c -Calor } \\
\text { Específico } \\
\text { (J/kg.K) }\end{array}$ & $\begin{array}{l}\lambda \text {-Condutividade } \\
\text { térmica }(\mathrm{W} / \mathrm{m} . \mathrm{K})\end{array}$ \\
\hline Isolamento cobertura & lã de rocha & 0,048 & 32 & 750 & 0,045 \\
\hline \multirow{3}{*}{ Alvenaria de bloco cerâmico } & Revestimento externo & 0,025 & 2000 & 1000 & 1,15 \\
\hline & Bloco cerâmico & 0,14 & 1600 & 920 & 0,9 \\
\hline & Revestimento interno & 0,025 & 2000 & 1000 & 1,15 \\
\hline
\end{tabular}

Fonte: as autoras.

\section{Resultados e discussões}

A apresentação e análise dos resultados foi dividida em: método simplificado com a análise da transmitância e capacidade térmica das paredes, aberturas para ventilação e transmitância térmica da cobertura; e simulação computacional com avaliação do desempenho no verão e no inverno.

\section{Método Simplificado: adequação das paredes externas}

Na Tabela 3 estão relacionados parâmetros e valores obtidos para a $U\left(\mathrm{~W} / \mathrm{m}^{2} . \mathrm{K}\right)$ e CT $\left(\mathrm{kJ} / \mathrm{m}^{2} . \mathrm{K}\right)$ das paredes externas, conforme as exigências da NBR15220 (ABNT, 2005), bem como a verificação do atendimento aos critérios da NBR 15575-4 (ABNT, 2013b) pelo método simplificado.

Tabela 3 - Verificação dos critérios da U e da CT para o SVVE da edificação avaliada

e $(m) \quad R t\left(m^{2} . K / W\right)$ R se $R$ si $R T\left(m^{2} . K / W\right) \quad U\left(W / m^{2} . K\right) \quad$ Critério da Transmitância térmica CT (kJ/m².K) Critério da Capacidade térmica

$\begin{array}{llllllll}0,10 & 0,057 & 0,13 & 0,04 & 0,227 & 4,403 & \text { Não atende } & 240,00\end{array}$

Fonte: as autoras.

Diante dos resultados apresentados, observa-se que segundo o critério da Transmitância, não há adequação das paredes externas, visto que $U$ é maior que 3,7 $\mathrm{W} / \mathrm{m}^{2}$.K. Para o critério da Capacidade térmica, como verificou-se que $\mathrm{CT}>130 \mathrm{~kJ} / \mathrm{m}^{2} . \mathrm{K}$, o critério foi atendido. Diante disso, faz-se necessário aplicar o método da simulação.

Método simplificado: aberturas para ventilação

A Tabela 4 relaciona os cálculos das aberturas para ventilação e os resultados para o critério apresentado na NBR 15575-4 (ABNT, 2013b). Observou-se que o critério da área de ventilação foi atendido em todos os APPs da edificação analisada.

\begin{tabular}{|c|c|c|c|c|c|c|}
\hline Ambiente & $\begin{array}{l}\text { Ap -Área do } \\
\text { piso }\left(\mathrm{m}^{2}\right)\end{array}$ & Tipo de esquadria & $\begin{array}{l}\text { Dimensões das } \\
\text { esquadrias (m) }\end{array}$ & $\begin{array}{c}\text { Aa - Área } \\
\text { aberturas }\left(\mathrm{m}^{2}\right)\end{array}$ & A - área de ventilação & Resultado \\
\hline $\begin{array}{l}\text { Hall/Sala/ } \\
\text { Cozinha }\end{array}$ & 19,59 & $\begin{array}{l}\text { Porta de correr } 2 \text { folhas vidro; } 2 \\
\text { Janelas correr } 2 \text { folhas vidro;/ Janela } \\
\text { correr } 2 \text { folhas vidro }\end{array}$ & $\begin{array}{l}0,70 \times 2,10 \\
1,00 \times 1,00 \\
1,00 \times 1,00\end{array}$ & 2,86 & $15 \%$ & Atende \\
\hline Quarto 1 & 8,50 & Janela correr 2 folhas vidro & $1,50 \times 1,00$ & 0,68 & $8 \%$ & Atende \\
\hline Quarto 2 & 10,26 & Janela correr 2 folhas vidro & $1,50 \times 1,00$ & 0,68 & $7 \%$ & Atende \\
\hline
\end{tabular}

Fonte: as autoras.

Método simplificado: transmitância térmica da cobertura

Na Tabela 5 estão demonstrados parâmetros e valores obtidos para a $U\left(\mathrm{~W} / \mathrm{m}^{2} . \mathrm{K}\right) \mathrm{da}$ cobertura, para o verão e inverno, conforme método de cálculo da NBR15220 (ABNT, 
OLIVEIRA, R. B. de; ALVES, C. dos R.

Análise do desempenho térmico de habitação de interesse social com paredes de concreto em Uberlândia-MG

2005), além da verificação do atendimento aos critérios da NBR 15575-5 (ABNT, 2013C) para o método simplificado.

Tabela 5 - Verificação do critério da U para cobertura da edificação avaliada

\begin{tabular}{|c|c|c|c|c|c|c|c|c|}
\hline \multicolumn{9}{|c|}{ VERÃO (Fluxo descendente $\downarrow$ ) } \\
\hline Telha - e (m) & $\operatorname{Rar}\left(m^{2} . K / W\right)$ & Laje - e (m) & R se & R si & Rt $\left(m^{2} \cdot K / W\right)$ & $\mathrm{RT}\left(\mathrm{m}^{2} \cdot \mathrm{K} / \mathrm{W}\right)$ & $\mathrm{U}\left(\mathrm{W} / \mathrm{m}^{2} . \mathrm{K}\right)$ & Resultado \\
\hline 0,012 & 0,21 & 0,100 & 0,04 & 0,017 & 0,309 & 0,366 & 2,736 & Não atende \\
\hline \multicolumn{9}{|c|}{ INVERNO (Fluxo ascendente $\uparrow$ ) } \\
\hline Telha - e (m) & $\operatorname{Rar}\left(m^{2} . K / W\right)$ & Laje - e (m) & R se & R si & $\mathrm{Rt}\left(\mathrm{m}^{2} . \mathrm{K} / \mathrm{W}\right)$ & $\mathrm{RT}\left(\mathrm{m}^{2} . \mathrm{K} / \mathrm{W}\right)$ & $\mathrm{U}\left(\mathrm{W} / \mathrm{m}^{2} . \mathrm{K}\right)$ & Resultado \\
\hline 0,012 & 0,14 & 0,100 & 0,04 & 0,10 & 0,239 & 0,379 & 2,642 & Não Atende \\
\hline
\end{tabular}

Fonte: as autoras.

Considerando que o critério de $\mathrm{U} \leq 1,5 \mathrm{~W} / \mathrm{m} 2 . \mathrm{K}$ não foi atendido, para a $\mathrm{UH}$ analisada, o requisito de transmitância térmica da cobertura não foi atendido. Portanto, é necessário verificar pelo método da simulação.

Simulação computacional: Desempenho térmico no verão

As simulações para o período de verão foram feitas conforme o período de outubro a abril definido anteriormente. A Figura 3 mostra as temperaturas obtidas para a situação real de projeto com beiral e paredes brancas (absortância 0,2).

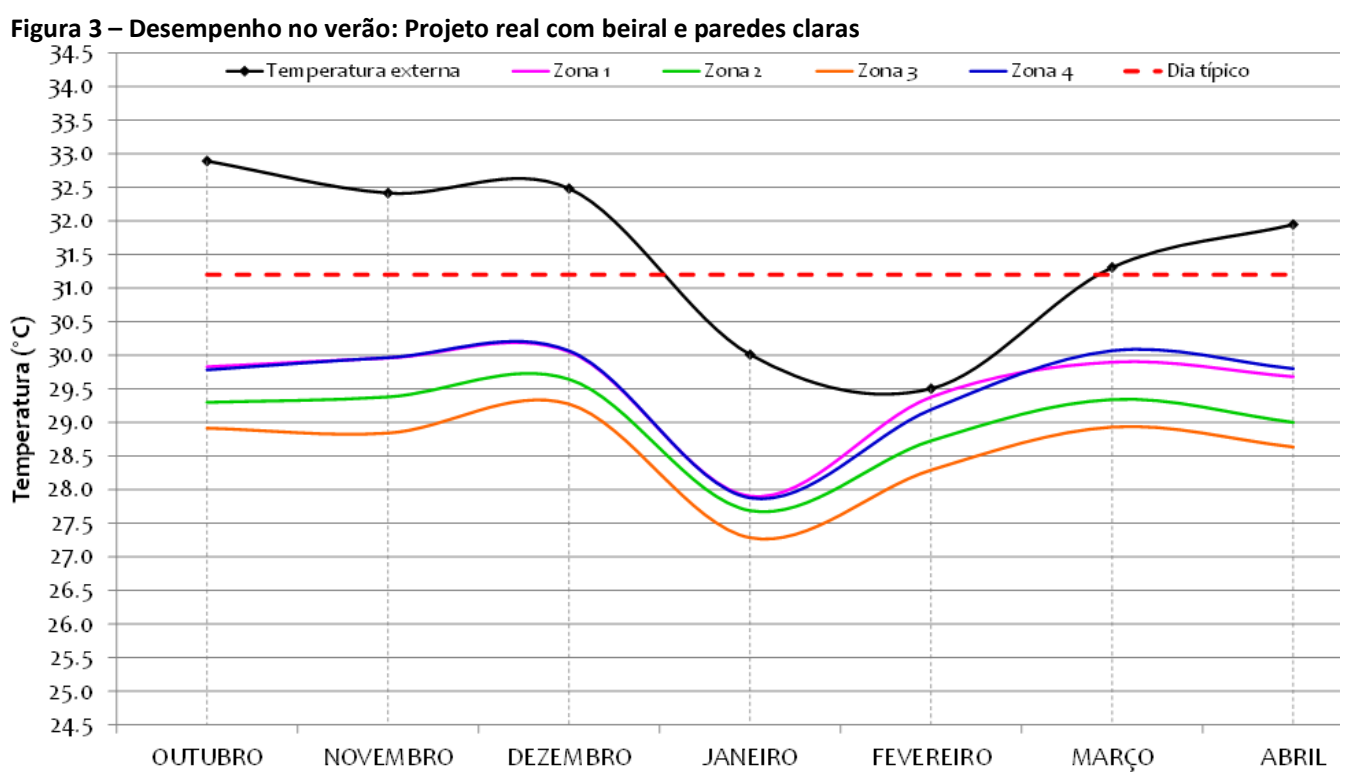

Fonte: as autoras.

Para essas condições, o desempenho térmico mínimo para o verão estaria atendido tanto em comparação das temperaturas internas com as externas, como com o dia típico.

Parte-se então para a verificação das mesmas condições com alteração da absortância para 0,7. Essa análise deve-se ao fato de que as edificações serão repintadas em algum momento e que comumente encontra-se HIS com cores escuras nas fachadas. A Figura 4 contém os resultados. 
OLIVEIRA, R. B. de; ALVES, C. dos R.

Análise do desempenho térmico de habitação de interesse social com paredes de concreto em Uberlândia-MG

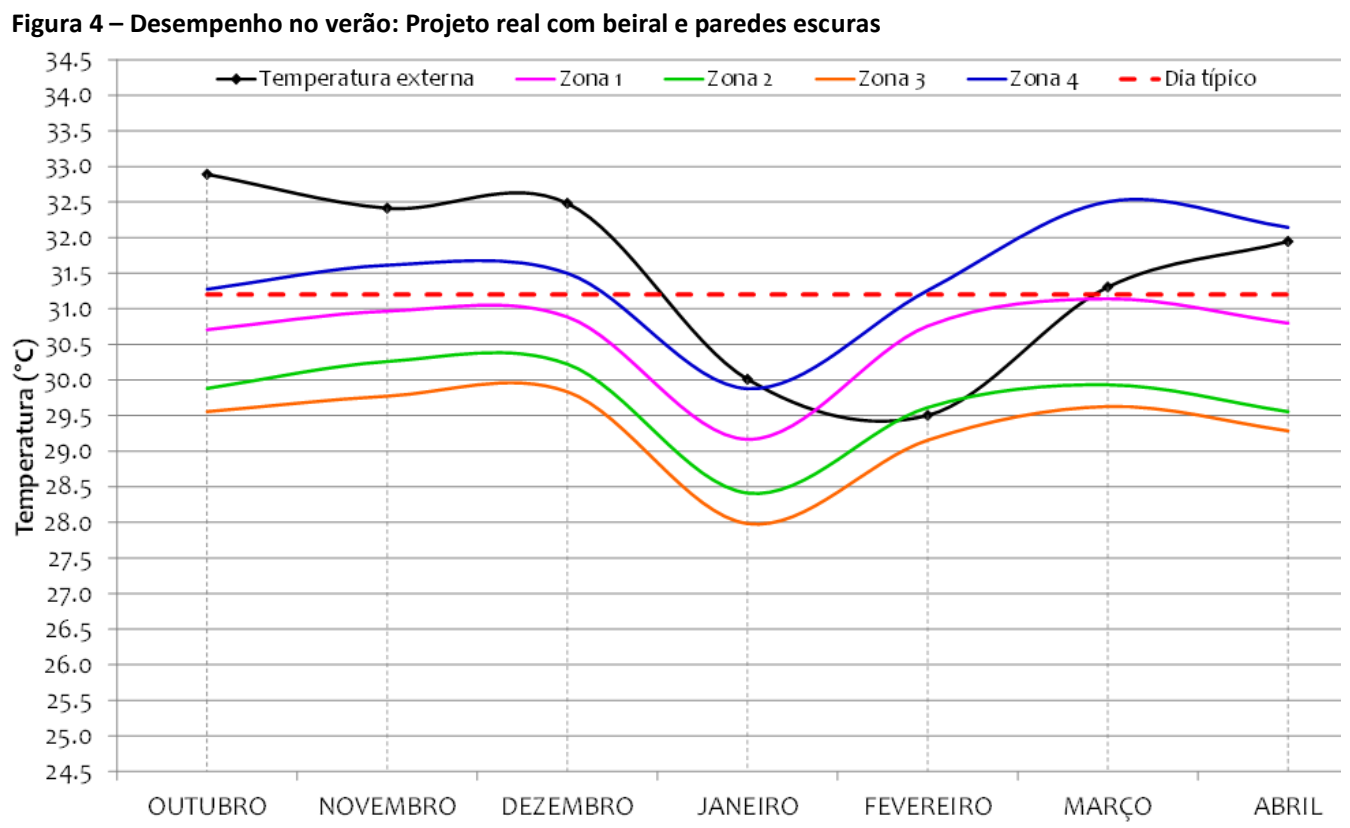

Fonte: as autoras.

Com a alteração da cor das paredes, nota-se aumentos nas temperaturas internas das zonas, levando ao não atendimento do nível mínimo no verão em nenhum dos dois critérios. Em comparação com as temperaturas externas, apenas a zona 3 teve temperaturas menores em todos os meses. Quanto ao dia típico, todas atenderiam com exceção da zona 4.

A Tabela 6 mostra as temperaturas máximas internas de cada zona para as duas situações. $O$ acréscimo de temperatura para paredes com absortância 0,7 foi unânime em todas as zonas, variando de $0,55^{\circ} \mathrm{C}$ (zona $2 \mathrm{em}$ abril) até $2,44^{\circ} \mathrm{C}$ (zona $4 \mathrm{em}$ março). As maiores diferenças de temperatura foram na zona 4 , onde o menor aumento foi de $1,43^{\circ} \mathrm{C}$ em dezembro.

\begin{tabular}{|c|c|c|c|c|c|c|c|c|}
\hline \multirow[b]{2}{*}{ Meses/ Absortância } & \multicolumn{2}{|c|}{ Zona 1} & \multicolumn{2}{|c|}{ Zona 2} & \multicolumn{2}{|c|}{ Zona 3} & \multicolumn{2}{|c|}{ Zona 4} \\
\hline & 0.2 & 0.7 & 0.2 & 0.7 & 0.2 & 0.7 & 0.2 & 0.7 \\
\hline OUTUBRO & 29.83 & 30.71 & 29.30 & 29.88 & 28.92 & 29.56 & 29.78 & 31.27 \\
\hline NOVEMBRO & 29.96 & 30.97 & 29.38 & 30.26 & 28.84 & 29.77 & 29.97 & 31.61 \\
\hline DEZEMBRO & 30.05 & 30.89 & 29.64 & 30.22 & 29.28 & 29.84 & 30.07 & 31.50 \\
\hline JANEIRO & 27.91 & 29.17 & 27.69 & 28.41 & 27.29 & 27.98 & 27.88 & 29.88 \\
\hline FEVEREIRO & 29.38 & 30.76 & 28.73 & 29.61 & 28.29 & 29.16 & 29.19 & 31.26 \\
\hline MARÇO & 29.90 & 31.14 & 29.34 & 29.93 & 28.93 & 29.63 & 30.07 & 32.51 \\
\hline ABRIL & 29.68 & 30.80 & 29.00 & 29.56 & 28.64 & 29.29 & 29.80 & 32.14 \\
\hline
\end{tabular}

Fonte: as autoras.

Sabe-se que a absortância tem um papel primordial no desempenho térmico e tais resultados comprovam esse fato. Nesse sentido, reforça-se que essa informação deve ser transmitida ao usuário por meio do manual de uso e operação, para que esteja ciente de que o simples fato de alterar a cor da casa para um tom mais escuro acarretaria em mudanças consideráveis na temperatura interna ao longo do ano.

Outro ponto a ser destacado refere-se à comum entrega de HIS com fachadas em cor escura. Para tanto, as avaliações de desempenho térmico devem seguir estritamente o que será executado, e, portanto, a cor deve ser indicada no projeto e não deve ser definida posteriormente, assegurando a confiabilidade da determinação da obtenção ou não de pelo menos o nível mínimo. 
OLIVEIRA, R. B. de; ALVES, C. dos R.

Análise do desempenho térmico de habitação de interesse social com paredes de concreto em Uberlândia-MG

Parte-se então para outra análise: a desconsideração dos beirais. Tal cenário foi simulado para avaliar a influência desse elemento arquitetônico nas temperaturas internas das edificações. Além de que, muitas das vezes é desconsiderado como forma de simplificação das simulações. Nesse sentido, foram feitas duas simulações sem a utilização do beiral, mantendo a comparação quanto à absortância solar das paredes. As Figuras 5 e 6 mostram as temperaturas internas obtidas para a situação sem beiral e paredes com absortância 0,2 e 0,7, respectivamente.

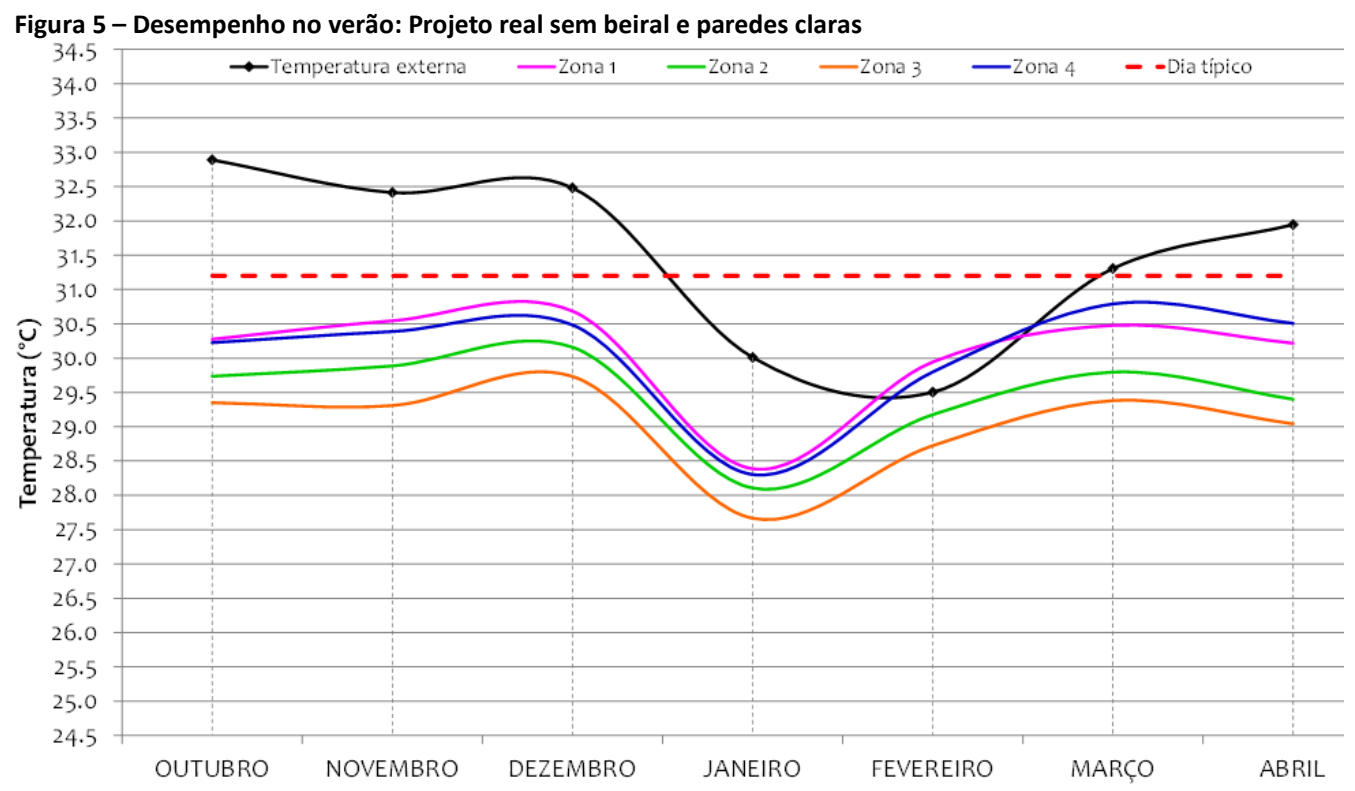

Fonte: as autoras.

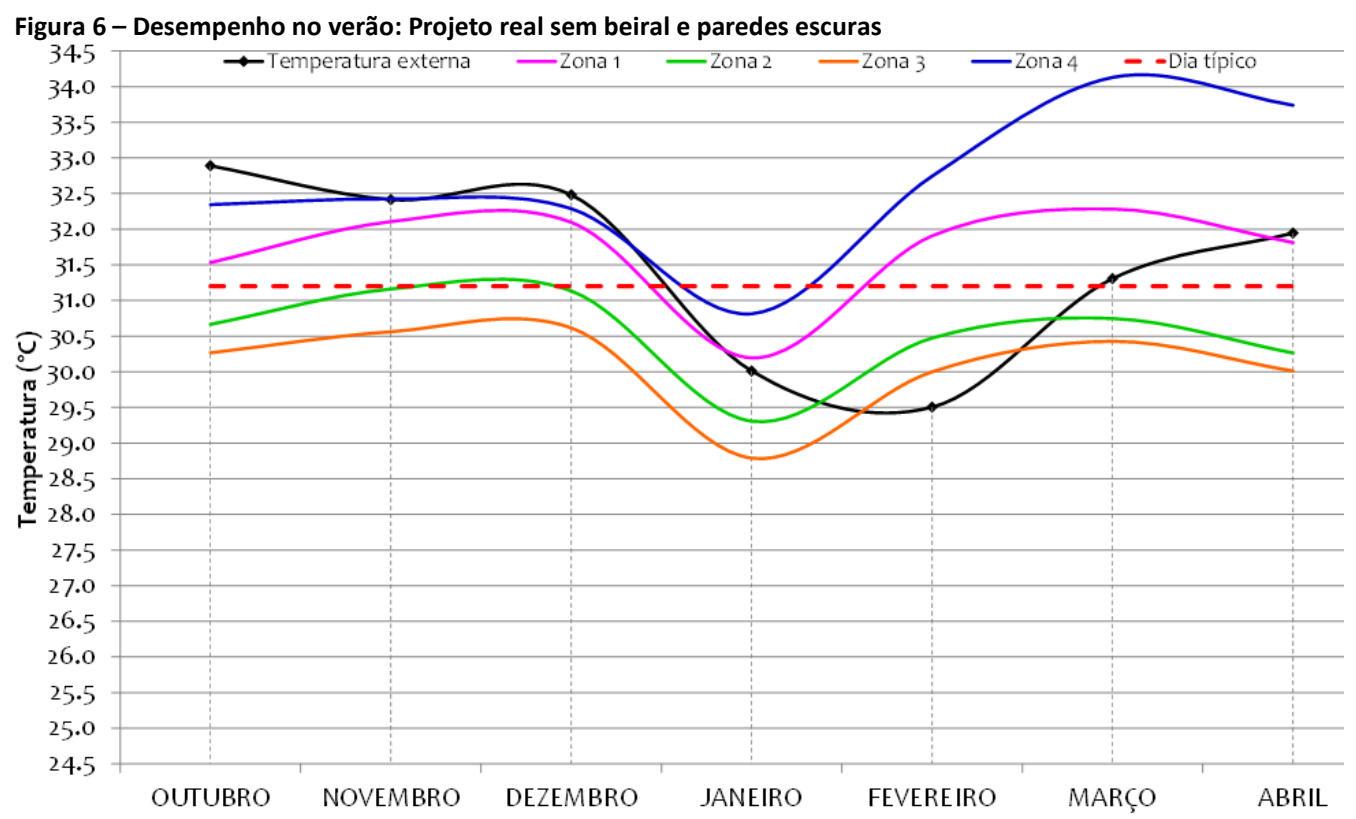

Fonte: as autoras.

Para a situação sem beiral e absortância 0,2, todas as zonas atenderam ao critério do dia típico. No entanto, entre os meses de janeiro e março, apesar de ser um período curto e com diferenças pequenas, as zonas 1 e 4 tiveram temperaturas internas máximas maiores que as temperaturas máximas externas, não atingindo, portanto, o nível mínimo. 
OLIVEIRA, R. B. de; ALVES, C. dos R.

Análise do desempenho térmico de habitação de interesse social com paredes de concreto em Uberlândia-MG

Já para o caso sem beiral e absortância 0,7 , nenhuma zona teve as suas temperaturas internas menores que as externas ao longo de todo o verão. Quanto ao dia típico, apenas a zona 3 estaria com desempenho mínimo, o que passa a não ser tão significativo por não se tratar de um APP.

Confrontando os resultados das quatro simulações apresentadas para as zonas 1, 2 e 4, equivalentes aos APPs da edificação, tem-se os valores de temperatura apresentados nas Figuras 7, 8 e 9. Analisando os dados expostos, como era o esperado, a edificação sem beiral e paredes com absortância 0,7 , foi responsável pelas temperaturas máximas mais altas em todo o ano para as três zonas, com exceção do mês de janeiro na zona 2.

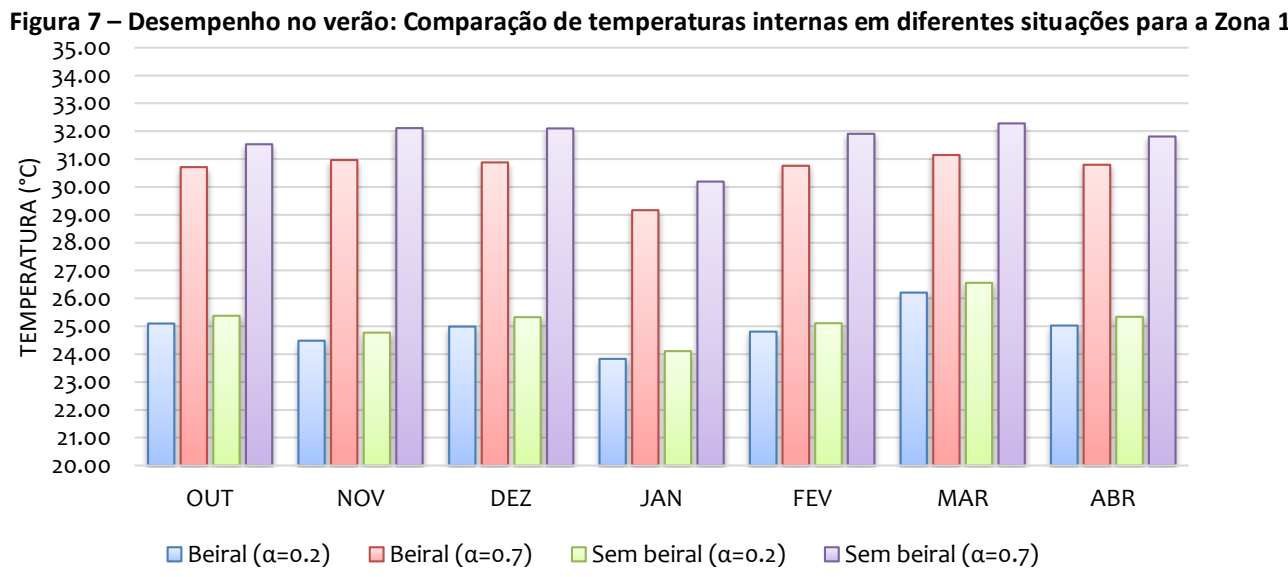

Fonte: as autoras.

Figura 8 - Desempenho no verão: Comparação de temperaturas internas em diferentes situações para a Zona 2

$$
\begin{aligned}
& 35.00 \\
& \begin{array}{l}
34.00 \\
33.00
\end{array} \\
& \text { ○ } 31.00 \\
& \text { 匹 } 29.00 \\
& 27.00 \\
& \text { 品 } 25.00 \\
& 24.00 \\
& 22.00 \\
& 20.00
\end{aligned}
$$$$
33.00
$$$$
\text { 兵 } 28.00
$$$$
23.00
$$$$
21.00
$$

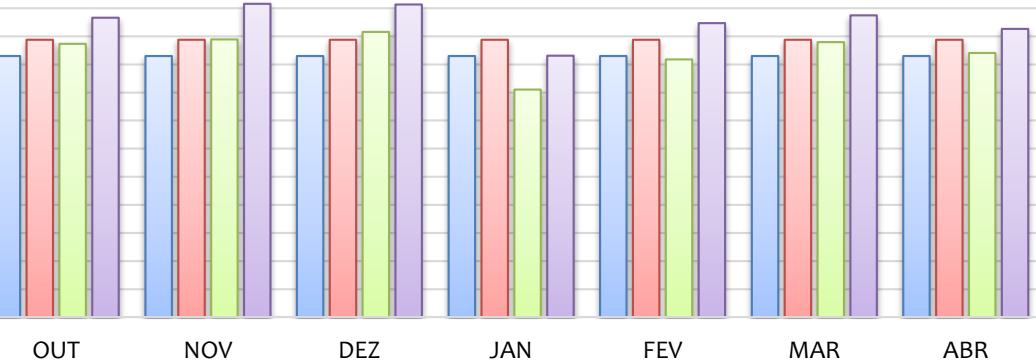

$\square$ Beiral ( $\alpha=0.2) \quad \square$ Beiral $(\alpha=0.7) \quad \square$ Sem beiral $(\alpha=0.2) \quad \square$ Sem beiral $(\alpha=0.7)$

Fonte: as autoras.

Figura 9 - Desempenho no verão: Comparação de temperaturas internas em diferentes situações para a Zona 4

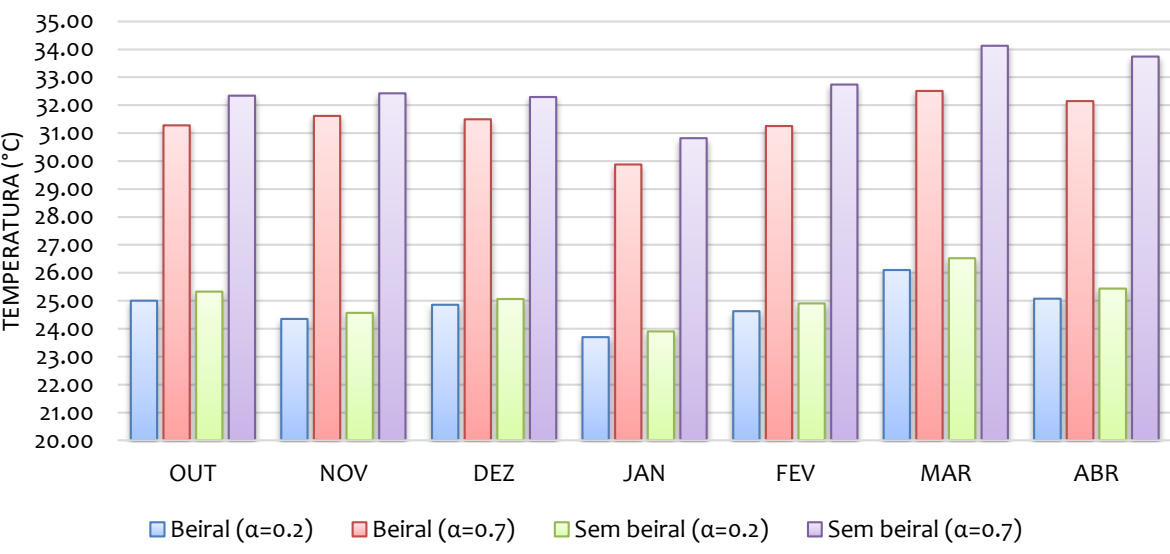

Fonte: as autoras. 
OLIVEIRA, R. B. de; ALVES, C. dos R.

Análise do desempenho térmico de habitação de interesse social com paredes de concreto em Uberlândia-MG

Quanto aos resultados dentro da mesma zona, é possível constatar que a absortância foi responsável por aumentos mais bruscos de temperatura, do que a presença ou não de beiral na edificação, para as zonas 1 e 4. Para a zona 2, as diferenças foram menores para as simulações realizadas, mas aquelas com absortância 0,7 foram responsáveis por maiores temperaturas internas.

Pode-se inferir que tais cenários são justificados pelas áreas de exposição de cada zona térmica e da sua orientação solar, cujos dados encontram-se na Tabela 7. A zona 1 tem a maior área exposta, porém distribuída nas quatro orientações, e com uma porcentagem menor nas mais críticas (oeste e norte), contrapondo-se à zona 4 que tem a maior área exposta nas mesmas fachadas. Enquanto isso, a zona 2 tem $100 \%$ da sua fachada externa voltada para o oeste, justificando as pequenas variações na temperatura interna apesar dos cenários simulados.

Tabela 7 - Áreas de exposição das fachadas e a orientação solar para as simulações no verão

\begin{tabular}{|c|c|c|c|c|c|}
\hline Zona & Fachada total $\left(\mathrm{m}^{2}\right)$ & $\begin{array}{c}\text { Proporção da Fachada } \\
\text { Norte (\%) }\end{array}$ & $\begin{array}{c}\text { Proporção da Fachada } \\
\text { Sul (\%) }\end{array}$ & $\begin{array}{c}\text { Proporção da Fachada } \\
\text { Leste (\%) }\end{array}$ & $\begin{array}{c}\text { Proporção da Fachada } \\
\text { Oeste (\%) }\end{array}$ \\
\hline 1 & 42.90 & 9.1 & 33.3 & 44.2 & 13.3 \\
\hline 2 & 9.10 & - & - & - & 100.0 \\
\hline 4 & 25.48 & 40.8 & - & 29.6 & 29.6 \\
\hline
\end{tabular}

Outros dois cenários simulados referem-se à substituição da vedação vertical para alvenaria de bloco cerâmico, e também ao isolamento da cobertura com lã de rocha acima da laje, para a verificação de possibilidades de melhoria do projeto real. O beiral foi mantido bem como a absortância 0,2 para as paredes externas. As Figuras 10 e 11 mostram as temperaturas para as simulações em questão.

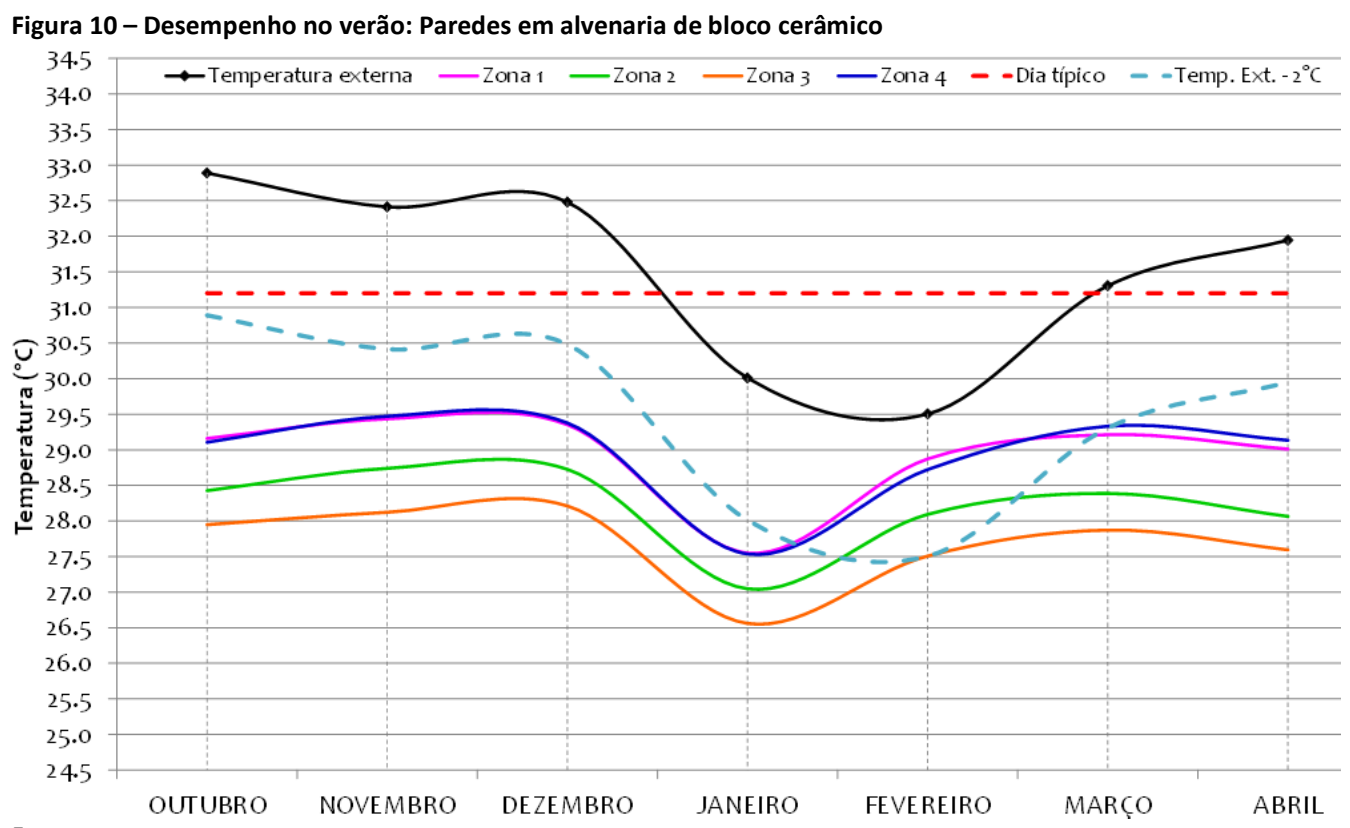

Fonte: as autoras. 
OLIVEIRA, R. B. de; ALVES, C. dos R.

Análise do desempenho térmico de habitação de interesse social com paredes de concreto em Uberlândia-MG

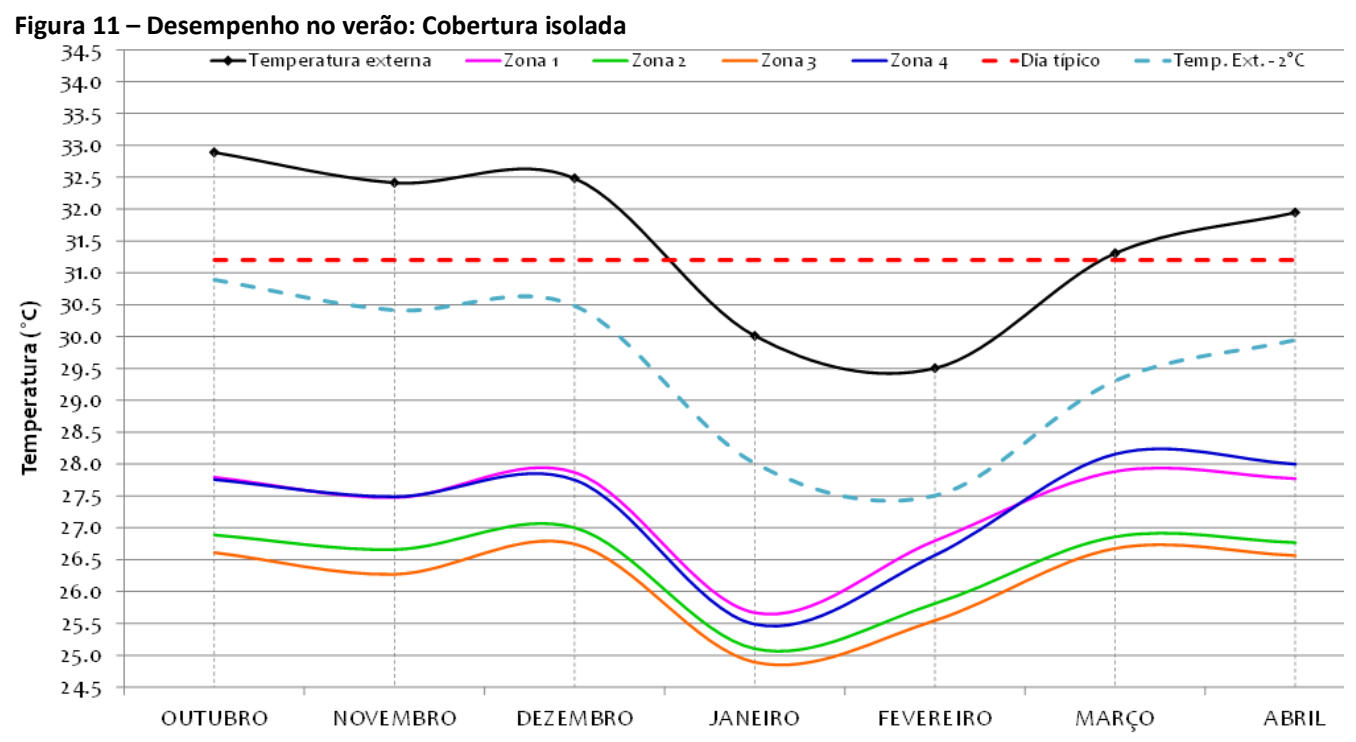

Fonte: as autoras.

A substituição do sistema de vedação vertical possibilitou redução das temperaturas internas de todas as zonas ao longo do verão. A menor queda foi de $0,34^{\circ} \mathrm{C}$ (zona $4 \mathrm{em}$ janeiro) e a maior de $1,06^{\circ} \mathrm{C}$ (zona 3 em dezembro), no entanto, não possibilitaram a obtenção do nível intermediário. A Tabela 8 traz os valores das temperaturas internas contrastando a situação real com o cenário em questão.

$\mathrm{O}$ isolamento da cobertura proporcionou os melhores resultados diante de todas as outras possibilidades. A redução variou de $1,80^{\circ} \mathrm{C}$ (zona $4 \mathrm{em}$ abril) até $2,92^{\circ} \mathrm{C}$ (zona $2 \mathrm{em}$ fevereiro), e por esta razão o desempenho térmico no nível intermediário foi alcançado inclusive. A Tabela 9 contém as temperaturas internas de todos os meses para as quatro zonas em comparação com a situação real.

\begin{tabular}{|c|c|c|c|c|c|c|c|c|}
\hline \multirow[b]{2}{*}{ Meses/Cenário } & \multicolumn{2}{|c|}{ Zona 1} & \multicolumn{2}{|c|}{ Zona 2} & \multicolumn{2}{|c|}{ Zona 3} & \multicolumn{2}{|c|}{ Zona 4} \\
\hline & Real & Alvenaria & Real & Alvenaria & Real & Alvenaria & Real & Alvenaria \\
\hline OUTUBRO & 29.83 & 29.16 & 29.30 & 28.43 & 28.92 & 27.95 & 29.78 & 29.11 \\
\hline NOVEMBRO & 29.96 & 29.44 & 29.38 & 28.74 & 28.84 & 28.12 & 29.97 & 29.47 \\
\hline DEZEMBRO & 30.05 & 29.35 & 29.64 & 28.73 & 29.28 & 28.21 & 30.07 & 29.38 \\
\hline JANEIRO & 27.91 & 27.55 & 27.69 & 27.05 & 27.29 & 26.56 & 27.88 & 27.54 \\
\hline FEVEREIRO & 29.38 & 28.87 & 28.73 & 28.09 & 28.29 & 27.51 & 29.19 & 28.72 \\
\hline MARÇO & 29.90 & 29.21 & 29.34 & 28.39 & 28.93 & 27.87 & 30.07 & 29.33 \\
\hline ABRIL & 29.68 & 29.01 & 29.00 & 28.06 & 28.64 & 27.59 & 29.80 & 29.13 \\
\hline
\end{tabular}

Fonte: as autoras.

Tabela 9 - Temperaturas máximas internas: situação real x cobertura isolada

\begin{tabular}{|c|c|c|c|c|c|c|c|c|}
\hline \multirow[b]{2}{*}{ Meses/ Cenário } & \multicolumn{2}{|r|}{ Zona 1} & \multicolumn{2}{|r|}{ Zona 2} & \multicolumn{2}{|r|}{ Zona 3} & \multicolumn{2}{|r|}{ Zona 4} \\
\hline & Real & Cobertura isolada & Real & Cobertura isolada & Real & Cobertura isolada & Real & Cobertura isolada \\
\hline OUTUBRO & 29.83 & 27.79 & 29.30 & 26.89 & 28.92 & 26.61 & 29.78 & 27.76 \\
\hline NOVEMBRO & 29.96 & 27.48 & 29.38 & 26.66 & 28.84 & 26.27 & 29.97 & 27.49 \\
\hline DEZEMBRO & 30.05 & 27.87 & 29.64 & 27.00 & 29.28 & 26.75 & 30.07 & 27.75 \\
\hline JANEIRO & 27.91 & 25.67 & 27.69 & 25.10 & 27.29 & 24.89 & 27.88 & 25.49 \\
\hline FEVEREIRO & 29.38 & 26.80 & 28.73 & 25.81 & 28.29 & 25.55 & 29.19 & 26.57 \\
\hline MARÇO & 29.90 & 27.88 & 29.34 & 26.86 & 28.93 & 26.68 & 30.07 & 28.16 \\
\hline ABRIL & 29.68 & 27.77 & 29.00 & 26.77 & 28.64 & 26.57 & 29.80 & 28.00 \\
\hline
\end{tabular}

Fonte: as autoras.

Simulação computacional: Desempenho térmico no inverno

As simulações para o período de inverno compreendem os meses de maio a setembro como definido anteriormente, para os mesmos cenários avaliados para o verão. Os 
OLIVEIRA, R. B. de; ALVES, C. dos R.

Análise do desempenho térmico de habitação de interesse social com paredes de concreto em Uberlândia-MG

resultados foram satisfatórios em termos da obtenção do nível mínimo pois todas as zonas térmicas apresentaram temperaturas internas maiores que as externas acrescidas de $3^{\circ} \mathrm{C}$. Avaliou-se também a possibilidade do alcance do desempenho intermediário, o que não foi possível para algumas zonas em alguns meses. As Figuras 12, 13, 14 e 15 mostram os resultados para o inverno para as seguintes situações: projeto real com beiral e absortância 0,2, projeto real com beiral e absortância 0,7, projeto real sem beiral e absortância 0,2, projeto real sem beiral e absortância 0,7, respectivamente.

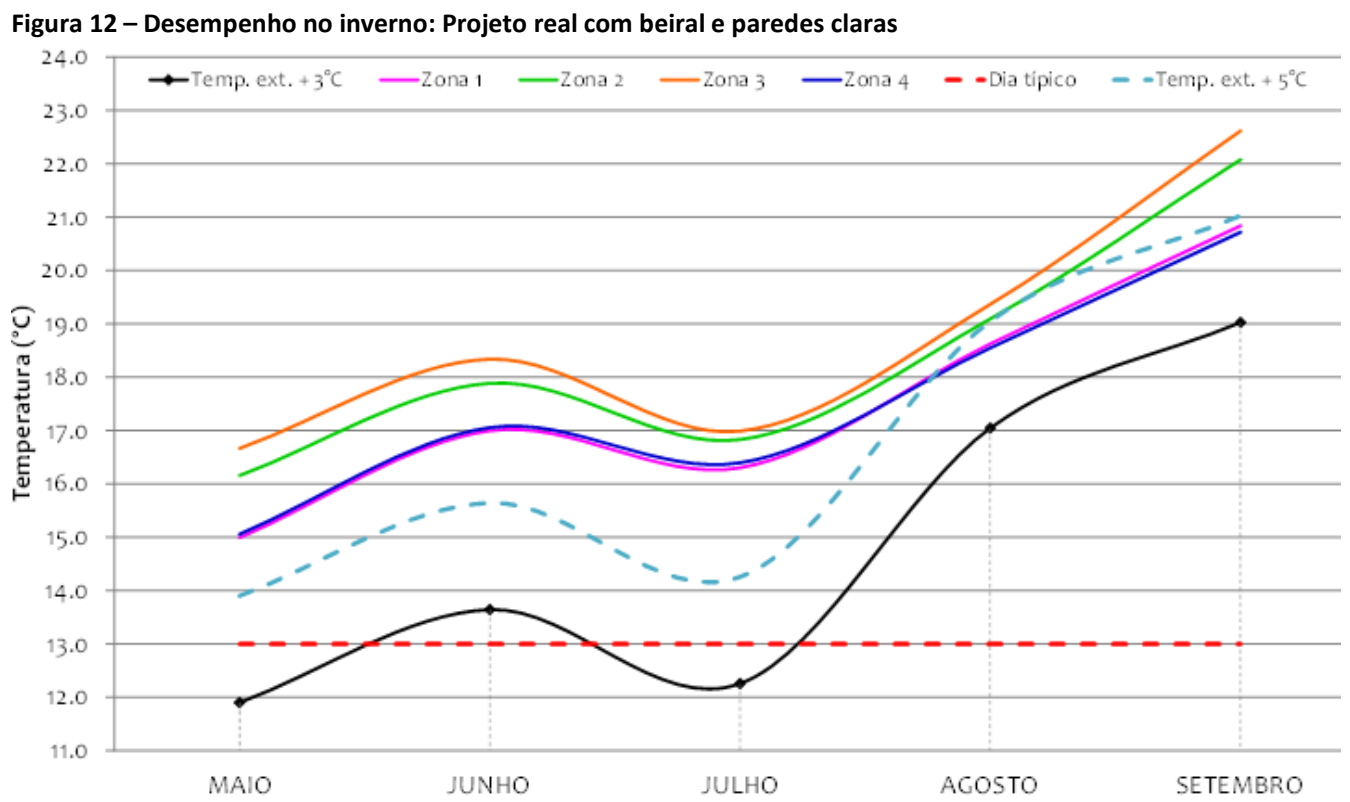

Fonte: as autoras.

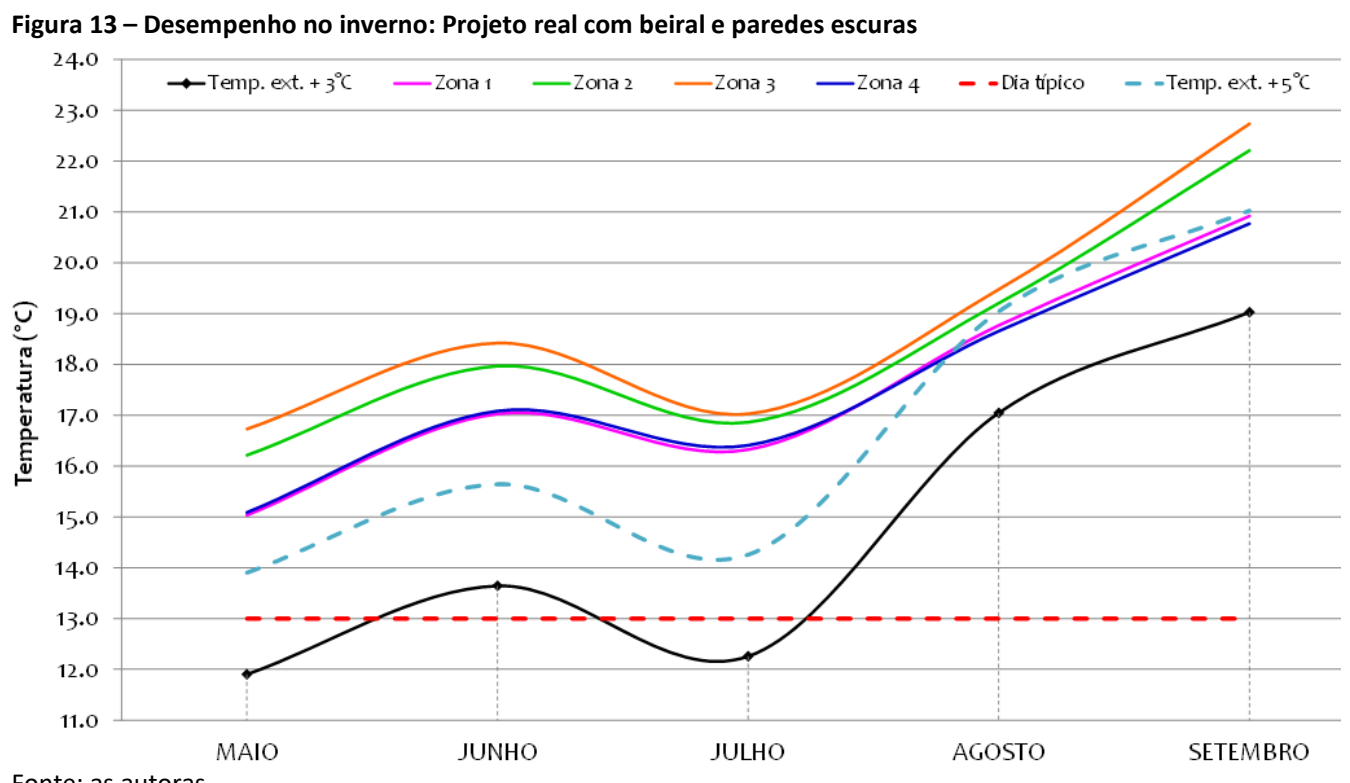

Fonte: as autoras. 
OLIVEIRA, R. B. de; ALVES, C. dos R.

Análise do desempenho térmico de habitação de interesse social com paredes de concreto em Uberlândia-MG

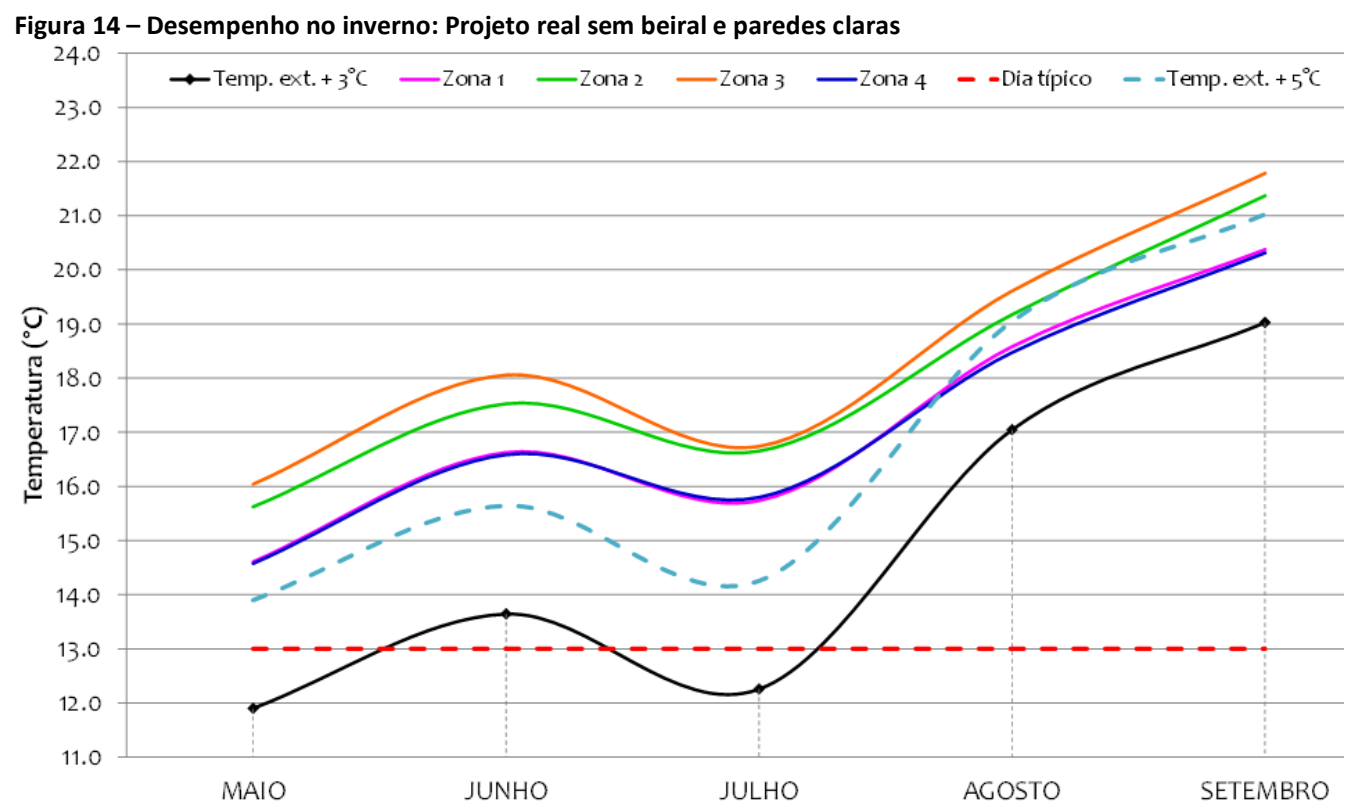

Fonte: as autoras.

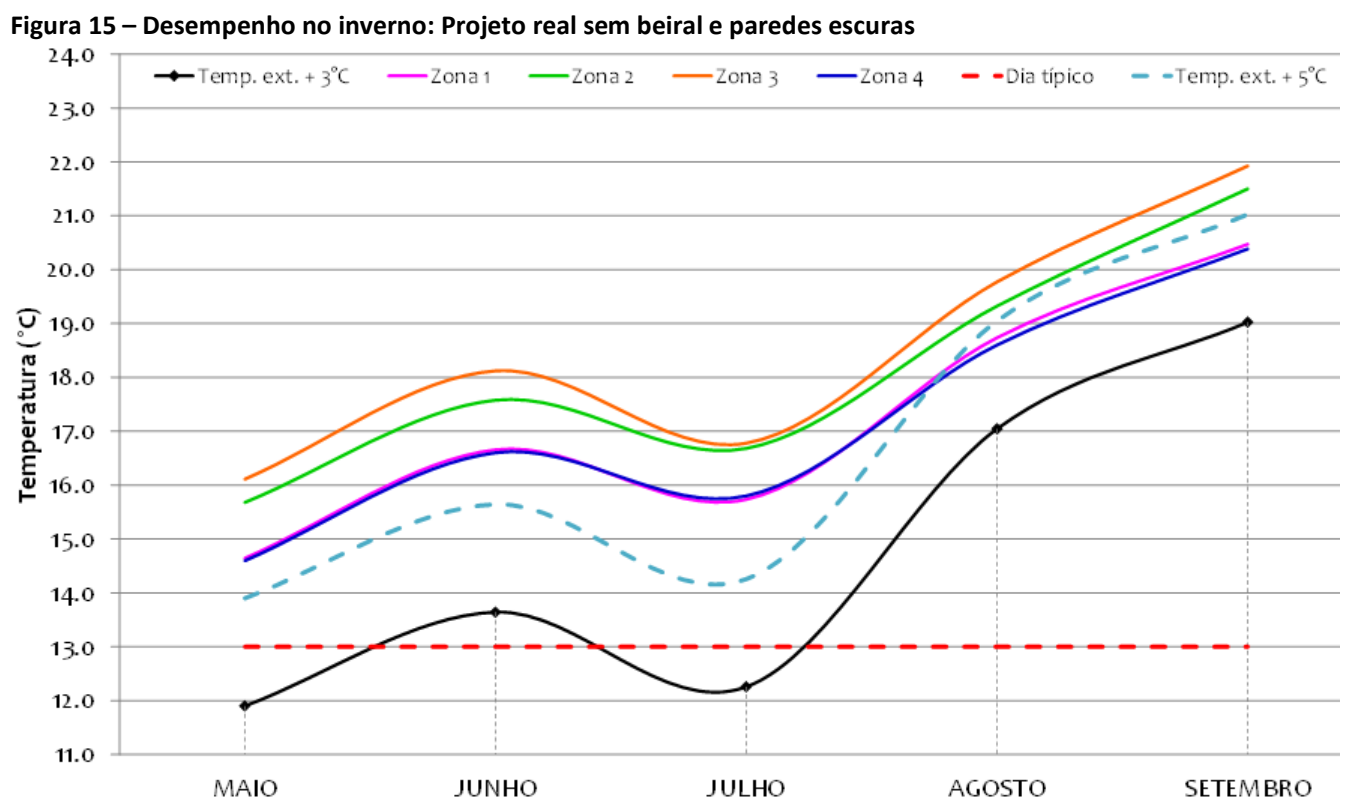

Fonte: as autoras.

Para o desempenho intermediário no inverno, novamente as zonas 1 e 4 foram as mais críticas devido às áreas de exposição para as orientações mais críticas (Tabela 10).

Tabela 10 - Áreas de exposição das fachadas e a orientação solar para as simulações no inverno

\begin{tabular}{cccccc}
\hline Zona & Fachada total $\left(\mathbf{m}^{2}\right)$ & $\begin{array}{c}\text { Proporção da Fachada } \\
\text { Norte (\%) }\end{array}$ & $\begin{array}{c}\text { Proporção da Fachada } \\
\text { Sul (\%) }\end{array}$ & $\begin{array}{c}\text { Proporção da Fachada } \\
\text { Leste (\%) }\end{array}$ & $\begin{array}{c}\text { Proporção da Fachada } \\
\text { Oeste (\%) }\end{array}$ \\
\hline 1 & 42.90 & 44.2 & 13.3 & 33.3 & - \\
\hline 2 & 9.10 & - & 100 & - & - \\
\hline 4 & 25.48 & 29.6 & 29.6 & - & 40.8 \\
\hline
\end{tabular}

Fonte: as autoras.

Como o desempenho mínimo para o inverno foi atendido nas quatro situações analisadas, a comparação das temperaturas internas mínimas possibilita uma visão mais ampla dos resultados, apresentadas nas Figuras 16, 17 e 18, para os APPs. 
OLIVEIRA, R. B. de; ALVES, C. dos R.

Análise do desempenho térmico de habitação de interesse social com paredes de concreto em Uberlândia-MG

No caso do inverno, constata-se que as maiores temperaturas internas para os APPs foram para as condições com as paredes externas claras (absortância 0,2). A absortância manteve sua influência dominante no desempenho térmico da edificação, comparada à presença ou não de beiral. No entanto, no mês de agosto por exemplo, para as três zonas, as temperaturas internas variaram muito pouco de $18,47^{\circ} \mathrm{C}$ a $18,82^{\circ} \mathrm{C}$. Ressalta-se, contudo, que apesar da dominância de um parâmetro em detrimento do outro, eles não foram significativos no inverno para que pudessem alterar o nível de desempenho térmico.

Figura 16 - Desempenho no inverno: Comparação de temperaturas internas em diferentes situações para a Zona 1

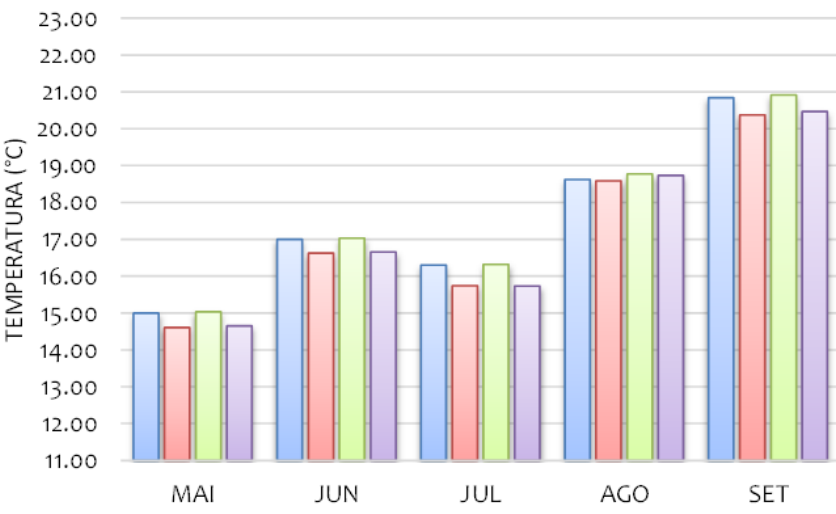

$\square$ Beiral $(\alpha=0.2) \square$ Beiral $(\alpha=0.7) \square$ Sem beiral $(\alpha=0.2) \square$ Sem beiral $(\alpha=0.7)$ Fonte: as autoras.

Figura 17 - Desempenho no inverno: Comparação de temperaturas internas em diferentes situações para a Zona 2

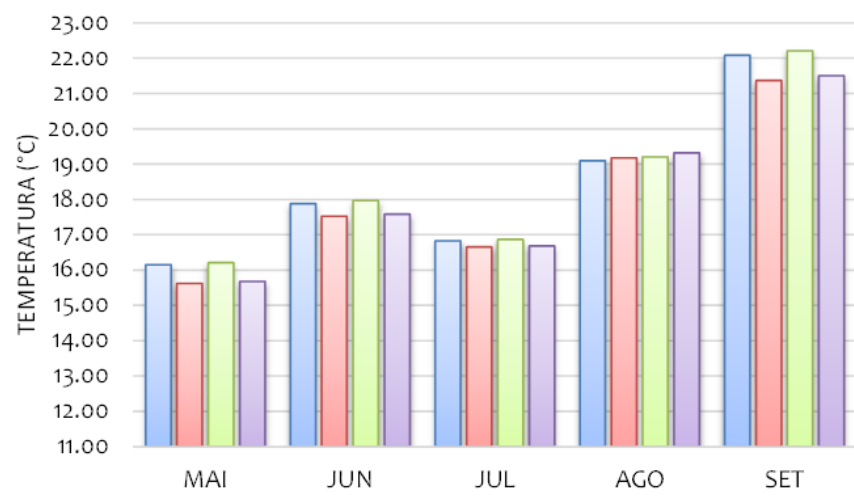

$\square$ Beiral $(\alpha=0.2) \square$ Beiral $(\alpha=0.7) \square$ Sem beiral $(\alpha=0.2) \square$ Sem beiral $(\alpha=0.7)$ Fonte: as autoras.

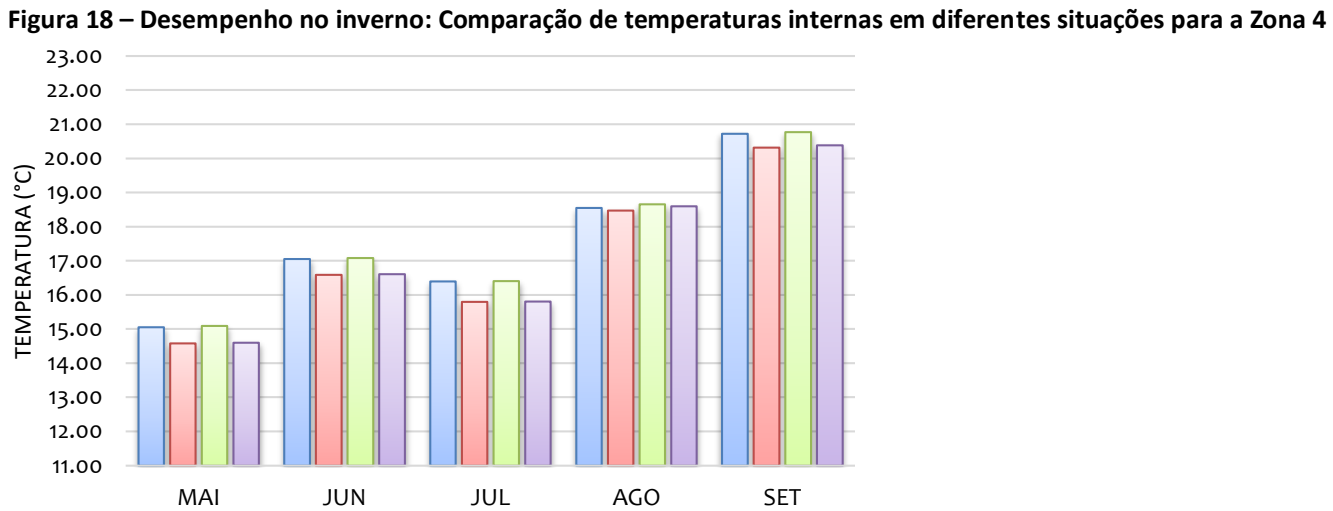

$\square$ Beiral ( $\alpha=0.2) \quad \square$ Beiral $(\alpha=0.7) \quad \square$ Sem beiral $(\alpha=0.2) \quad \square$ Sem beiral $(\alpha=0.7)$ Fonte: as autoras. 
OLIVEIRA, R. B. de; ALVES, C. dos R.

Análise do desempenho térmico de habitação de interesse social com paredes de concreto em Uberlândia-MG

Foram simuladas também as duas possibilidades de alteração do projeto real com a substituição do sistema de vedação vertical para alvenaria de bloco cerâmico (Figura 19) e isolamento da cobertura (Figura 20) em consonância com as avaliações feitas para o verão.

Em comparação com o projeto real com beiral e absortância 0,2, a substituição da vedação vertical provocou diminuição nas temperaturas internas de $0,14^{\circ} \mathrm{C}$ a $0,94^{\circ} \mathrm{C}$. Já o isolamento da cobertura, ocasionou redução em algumas situações $\operatorname{como} 0,67^{\circ} \mathrm{C}$ na zona 3 em setembro e $0,51^{\circ} \mathrm{C}$ na zona 2 no mesmo mês, mas também aumento como $0,61^{\circ} \mathrm{C}$ na zona $2 \mathrm{em}$ maio. Essas diferenças podem ser percebidas nas Tabelas 11 e 12. Contudo, as observações permanecem de que o desempenho mínimo foi atingido, mas o intermediário não foi possível.

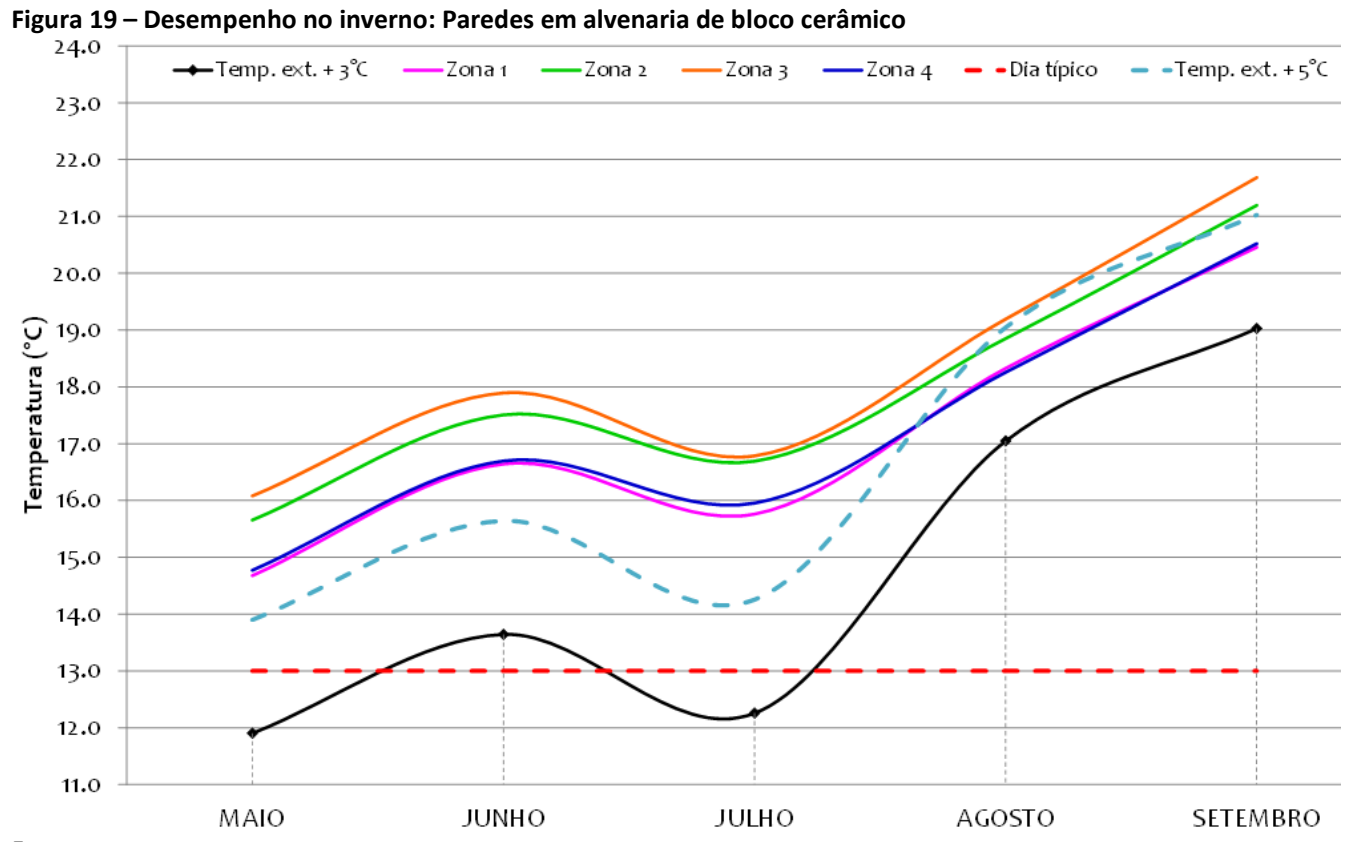

Fonte: as autoras.

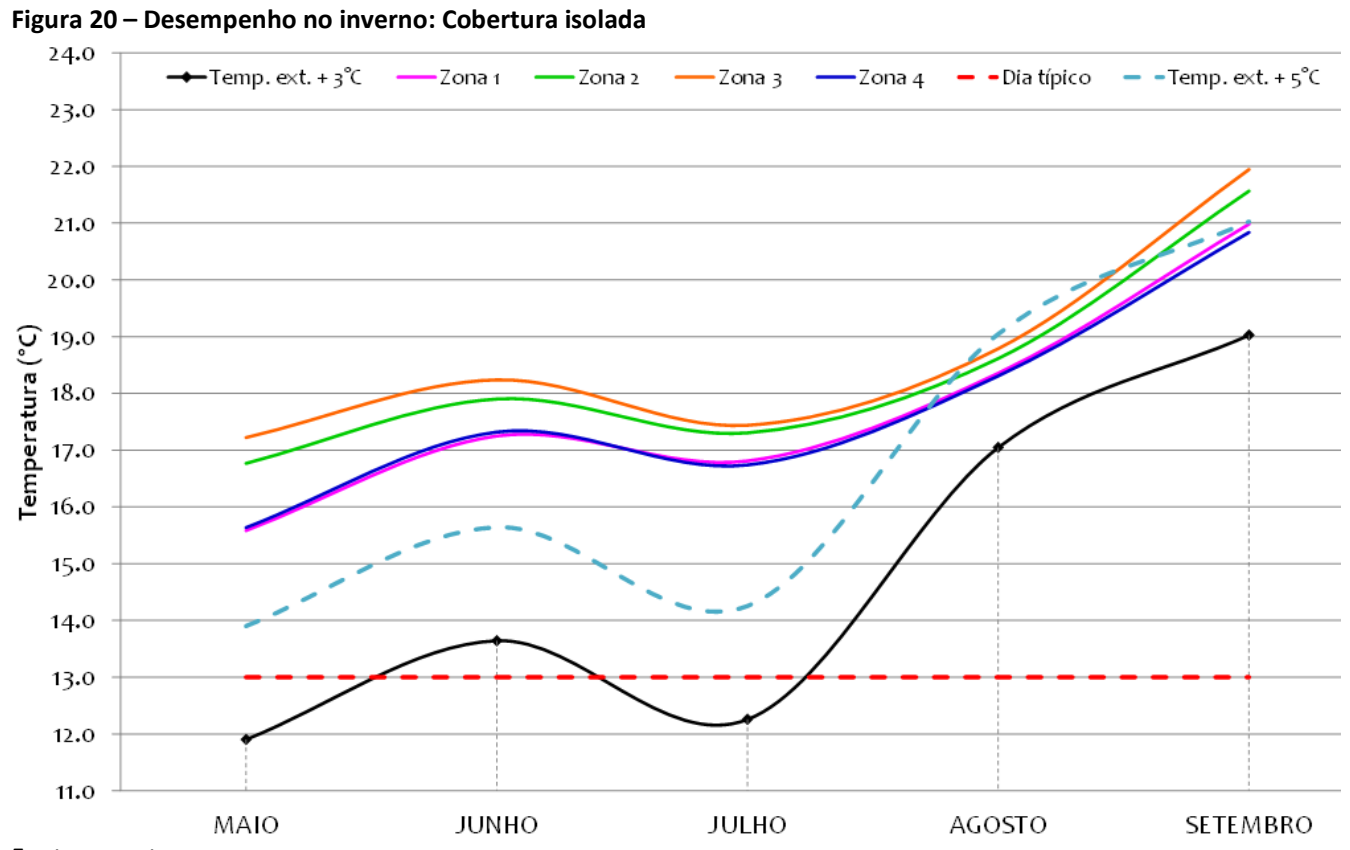

Fonte: as autoras. 
OLIVEIRA, R. B. de; ALVES, C. dos R.

Análise do desempenho térmico de habitação de interesse social com paredes de concreto em Uberlândia-MG

Tabela 11 - Temperaturas mínimas internas: situação real $\mathrm{x}$ alvenaria de bloco cerâmico

\begin{tabular}{|c|c|c|c|c|c|c|c|c|}
\hline \multirow[b]{2}{*}{ Meses/Cenário } & \multicolumn{2}{|c|}{ Zona 1} & \multicolumn{2}{|c|}{ Zona 2} & \multicolumn{2}{|c|}{ Zona 3} & \multicolumn{2}{|c|}{ Zona 4} \\
\hline & Real & Alvenaria & Real & Alvenaria & Real & Alvenaria & Real & Alvenaria \\
\hline MAIO & 14.99 & 14.68 & 16.16 & 15.66 & 16.67 & 16.08 & 15.05 & 14.77 \\
\hline JUNHO & 17.00 & 16.64 & 17.89 & 17.51 & 18.34 & 17.89 & 17.05 & 16.70 \\
\hline JULHO & 16.30 & 15.76 & 16.83 & 16.69 & 16.99 & 16.78 & 16.40 & 15.95 \\
\hline AGOSTO & 18.63 & 18.33 & 19.09 & 18.85 & 19.37 & 19.19 & 18.55 & 18.26 \\
\hline SETEMBRO & 20.84 & 20.46 & 22.08 & 21.19 & 22.62 & 21.68 & 20.72 & 20.52 \\
\hline
\end{tabular}

Fonte: as autoras.

Tabela 12 - Temperaturas mínimas internas: situação real x cobertura isolada

\begin{tabular}{|c|c|c|c|c|c|c|c|c|}
\hline & & Zona 1 & & Zona 2 & & Zona 3 & & Zona 4 \\
\hline Meses/Cenário & Real & Cobertura isolada & Real & Cobertura isolada & Real & Cobertura isolada & Real & Cobertura isolada \\
\hline MAIO & 14.99 & 15.58 & 16.16 & 16.77 & 16.67 & 17.22 & 15.05 & 15.64 \\
\hline JUNHO & 17.00 & 17.25 & 17.89 & 17.90 & 18.34 & 18.24 & 17.05 & 17.32 \\
\hline JULHO & 16.30 & 16.81 & 16.83 & 17.31 & 16.99 & 17.44 & 16.40 & 16.74 \\
\hline AGOSTO & 18.63 & 18.36 & 19.09 & 18.62 & 19.37 & 18.79 & 18.55 & 18.31 \\
\hline SETEMBRO & 20.84 & 20.98 & 22.08 & 21.57 & 22.62 & 21.94 & 20.72 & 20.84 \\
\hline
\end{tabular}

Fonte: as autoras.

Por fim, para uma compilação de todas as simulações realizadas, tem-se o Quadro 3. Além das análises já exploradas, nota-se também que a utilização da temperatura do dia típico para o verão possibilita conclusões diferentes quanto a comparação com as temperaturas externas, reafirmando as críticas feitas quanto aos resultados destoantes de acordo com o critério normativo escolhido. Os resultados para o verão corroboram com as constatações de Ferreira e Pereira (2012), onde o desempenho das paredes de concreto foi apenas mínimo nas ZBs de 1 a 4.

Quadro 3 - Compilação das simulações feitas e resultados obtidos para o verão e inverno

\begin{tabular}{|c|c|c|c|c|c|c|}
\hline & & \multirow{2}{*}{ Zona/ Critério } & \multicolumn{2}{|c|}{ DESEMPENHO MÍNIMO VERÃO } & \multicolumn{2}{|c|}{ DESEMPENHO MÍNIMO INVERNO } \\
\hline & & & Temperatura Externa & Dia típico & Temperatura Externa & Dia típico \\
\hline \multirow{8}{*}{ 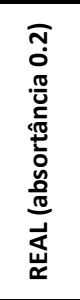 } & \multirow{4}{*}{ 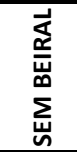 } & Zona 1 & NÃO & SIM & SIM & SIM \\
\hline & & Zona 2 & SIM & SIM & SIM & SIM \\
\hline & & Zona 3 & SIM & SIM & SIM & SIM \\
\hline & & Zona 4 & NÃO & SIM & SIM & SIM \\
\hline & \multirow{4}{*}{ 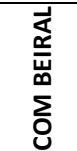 } & Zona 1 & $\mathrm{SIM}$ & SIM & SIM & SIM \\
\hline & & Zona 2 & SIM & SIM & SIM & SIM \\
\hline & & Zona 3 & SIM & SIM & SIM & SIM \\
\hline & & Zona 4 & SIM & SIM & SIM & SIM \\
\hline \multirow{8}{*}{ 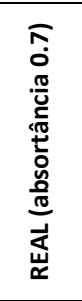 } & \multirow{4}{*}{ 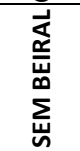 } & Zona 1 & NÃO & NÃO & SIM & SIM \\
\hline & & Zona 2 & NÃO & NÃO & SIM & SIM \\
\hline & & Zona 3 & NÃO & SIM & SIM & SIM \\
\hline & & Zona 4 & NÃO & NÃO & SIM & SIM \\
\hline & \multirow{4}{*}{ 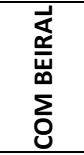 } & Zona 1 & NÃO & SIM & SIM & SIM \\
\hline & & Zona 2 & NÃO & SIM & SIM & SIM \\
\hline & & Zona 3 & SIM & SIM & SIM & SIM \\
\hline & & Zona 4 & NÃO & NÃO & SIM & SIM \\
\hline \multirow{8}{*}{ 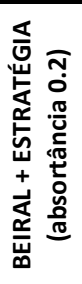 } & \multirow{4}{*}{ 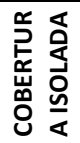 } & Zona 1 & $\mathrm{SIM}^{*}$ & SIM & SIM & SIM \\
\hline & & Zona 2 & $\mathrm{SIM}^{*}$ & SIM & SIM & SIM \\
\hline & & Zona 3 & SIM* & SIM & SIM & SIM \\
\hline & & Zona 4 & $\mathrm{SIM}^{*}$ & SIM & SIM & SIM \\
\hline & \multirow{4}{*}{ 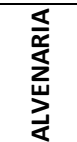 } & Zona 1 & SIM & SIM & SIM & SIM \\
\hline & & Zona 2 & SIM & SIM & SIM & SIM \\
\hline & & Zona 3 & SIM & SIM & SIM & SIM \\
\hline & & Zona 4 & SIM & SIM & SIM & SIM \\
\hline
\end{tabular}

Nota: * nível intermediário também foi alcançado. Fonte: as autoras.

\section{Conclusão}

A avaliação do desempenho térmico pelo método simplificado apontou para o não cumprimento do nível mínimo segundo os critérios normativos, diferentemente do que foi verificado pelo método de simulação. Portanto, há a necessidade de readequação 
dos limites do método simplificado para que este se torne mais completo, especialmente para avaliações de projetos simples como de HIS unifamiliares, em que uma mesma tipologia é amplamente replicada. Além disso, pondera-se que a orientação solar é decisiva e tal método não a considera.

Diante dos resultados apresentados para a simulação computacional, o projeto real com beiral atinge o mínimo para as condições de verão e inverno quando consideradas paredes com absortância 0,2. Entretanto, outras situações foram avaliadas, cujos resultados não foram satisfatórios. A mesma edificação, com paredes escuras (absortância 0,7 ), por exemplo, não atingiu os requisitos mínimos para o verão.

Nota-se também uma divergência quando comparadas as temperaturas internas com as externas, ou com o dia típico, como no cenário sem beiral, com absortância 0,2. Nesse mesmo sentido, outros resultados semelhantes foram obtidos, evidenciando-se então que cada avaliador diante de uma situação específica poderia utilizar o método ou critério que fosse mais conveniente, uma vez que as fronteiras consideradas para o "dia típico" apresentam extremos de temperatura. Sendo assim, diferentes níveis de desempenho poderiam ser obtidos para uma mesma UH a depender do critério escolhido.

Pode-se afirmar ainda que para a edificação em questão, com a orientação solar considerada, a cor das paredes foi mais decisiva na manutenção das temperaturas internas dos APPs no verão do que a utilização do beiral. Reforça-se, contudo, que a área de exposição das fachadas de cada zona também foi decisiva para esses fatores, principalmente para a zona 4 que em todas as análises para o verão foi a mais crítica.

O cenário com a cobertura isolada apresentou-se promissor elevando o nível de desempenho térmico ao intermediário para o verão. Apesar do custo a ser analisado, ressalta-se que essa solução não altera o sistema construtivo e nem a velocidade de produção, um dos objetivos principais do sistema de paredes de concreto. Já para o inverno, apesar de ocasionar reduções das temperaturas internas em alguns meses, também aumentou em outros, o que passa também a ser benéfico, apesar de não ter alterado o nível de desempenho.

Por fim, os resultados corroboram com outros estudos mencionados, afirmando que a estação do verão é de fato crítica para a ZB 4, e que as plantas comuns para HIS com paredes de concreto só atingem o nível mínimo de desempenho térmico, sem outra solução incorporada, com características decisivas como a absortância solar.

Como pesquisas futuras, sugere-se a exploração da significância do aumento da temperatura ocasionada pela mudança da absortância ou inserção do beiral, análises que incorporem os fenômenos do transporte de umidade e a interdependência entre eles, bem como a avaliação do custo-benefício das possibilidades simuladas.

\section{Agradecimentos}

À Coordenação de Aperfeiçoamento de Pessoal de Nível Superior (CAPES) pelo fomento de bolsa de pós-graduação às autoras (Número dos processos: 88882.383758/2019-01 e 88882.441383/2019-01).

\section{Nota}

Este artigo é uma versão estendida do artigo "DESEMPENHO TÉRMICO DE UMA HIS COM PAREDES DE CONCRETO EM UBERLÂNDIA-MG: UMA COMPARAÇÃO ENTRE RESULTADOS OBTIDOS E REQUISITOS EXISTENTES" (OLIVEIRA; ALVES, 2019) pelos autores apresentado no $2^{\circ}$ WORKSHOP DE TECNOLOGIA DE PROCESSOS E SISTEMAS CONSTRUTIVOS em 2019 em São Paulo. 


\section{Referências}

ABNT. ASSOCIAÇÃO BRASILEIRA DE NORMAS TÉCNICAS. NBR 15220-2: Desempenho térmico de edificações (Parte 2: Métodos de cálculo da transmitância térmica, da capacidade térmica, do atraso térmico e do fator solar de elementos e componentes de edificações. 1 ed. 21 p. Rio de Janeiro, 2005.

ABNT. ASSOCIAÇÃO BRASILEIRA DE NORMAS TÉCNICAS. NBR 15575-1: Edificações habitacionais - Desempenho (Parte 1: Requisitos gerais). 1 ed. 60 p. Rio de Janeiro, $2013 a$.

ABNT. ASSOCIAÇÃO BRASILEIRA DE NORMAS TÉCNICAS. NBR 15575-4: Edificações habitacionais - Desempenho (Parte 4: Sistemas de vedações verticais internas e externas - SVVIE). 1 ed. 57 p. Rio de Janeiro, 2013 b.

ABNT. ASSOCIAÇÃO BRASILEIRA DE NORMAS TÉCNICAS. NBR 15575-5: Edificações habitacionais -Desempenho Parte 5: Requisitos para sistemas de coberturas. Rio de Janeiro, $2013 \mathrm{C}$.

ALVES, C.R. Avaliação do comportamento higrotérmico de concretos produzidos com resíduos de borracha de pneu e poliestireno expandido para aplicação em paredes de concreto. 2020. $201 \mathrm{f}$. Dissertação (Mestrado) - Curso de Engenharia Civil, Faculdade de Engenharia Civil, Universidade Federal de Uberlândia, Uberlândia, 2020.

BRAGA, D. K.; AMORIM, C. N. D. Conforto térmico em edifícios residenciais do plano piloto de Brasília. In: CONFERÊNCIA LATINO-AMERICANA DE CONSTRUÇÃO SUSTENTÁVEL. 1.; ENCONTRO NACIONAL DE TECNOLOGIA DO AMBIENTE CONSTRUÍDO, 10., 2004, São Paulo. Anais [...]. São Paulo: ANTAC, 2014. p.18-21.

FERREIRA, C. C.; PEREIRA, I. M. Avaliação de desempenho térmico de habitação de interesse social de acordo com a NBR 15575, para as diversas zonas bioclimáticas. In: ENCONTRO NACIONAL DE TECNOLOGIA DO AMBIENTE CONSTRUÍDO, 14., 2012, Juiz de Fora. Anais [...]. Porto Alegre: ANTAC, 2012. p. 3590-3595.

GUARDA, E. L. A. DA; DURANTE, L. C.; CALLEJAS, I. J. A. Parâmetros climáticos para simulação de desempenho térmico segundo a NBR 15.575. PARC Pesquisa em Arquitetura e Construção, v. 11, p. e019014, 6 ago. 2020. DOI: https://doi.org/10.20396/parc.v11io.8655374

LORENZI, L. S. SILVA FILHO, L. C. P. Análise de desempenho de paredes de concreto armado frente a ABNT NBR 15575. In: CONGRESSO BRASILEIRO DO CONCRETO, 57., 2015, Bonito. Anais [...]. São Paulo: IBRACON, 2015.

OLIVEIRA, R. B.; ALVES, C. R. Desempenho térmico de uma HIS com paredes de concreto em Uberlândia-MG: uma comparação entre resultados obtidos e requisitos existentes. In: WORKSHOP DE TECNOLOGIA DE PROCESSOS E SISTEMAS CONSTRUTIVOS, 2., 2019, São Paulo. Anais [...']. São Paulo: TECSIC-ANTAC, 2019.

OLIVEIRA, R. B.; SALOMAO, M. C. F. Avaliação do dia típico da ABNT NBR 15575:2013 para a análise de desempenho térmico de edificações. In: MOSTRA CIENTÍFICA DA FACULDADE DE ENGENHARIA CIVIL DA UNIVERSIDADE DE UBERLÂNDIA, 2018, Uberlândia. Anais [...]. Uberlândia: UFU, 2018.

OLIVEIRA, R. D. et al. Análise do desempenho térmico de envoltórias em concreto no Brasil. In: ENCONTRO NACIONAL DE TECNOLOGIA DO AMBIENTE CONSTRUÍDO, 14., 2014, Maceió Anais [...]. Maceio: ANTAC, 2014. p. $1655-1664$.

OLIVEIRA, R. D. et al. Concrete walls thermal performance analysis by Brazilian Standards. Energy Procedia, v. 78, p. 213-218, 2015. DOI: https://doi.org.ez54.periodicos.capes.gov.br/10.1016/j.egypro.2015.11.383

PBE EDIFICA. Manual para Aplicação do RTQ-R. Disponível em: http://www.pbeedifica.com.br/sites/default/files/projetos/etiquetagem/residencial/downloads/Manual_RTQR_10201 4.pdf . Acesso em 18 de agosto de 2020.

QUEIRÓZ, G. R.; GRIGOLETTI, G. C.; SANTOS, J. C. P. Interoperabilidade entre os programas Autodesk Revit e EnergyPlus para simulação térmica de edificações. PARC Pesquisa em Arquitetura e Construção, vol. 10, p. e019005, 2019. DOI: http://dx.doi.org/10.20396/parc.v10io.8652852 
OLIVEIRA, R. B. de; ALVES, C. dos R.

Análise do desempenho térmico de habitação de interesse social com paredes de concreto em Uberlândia-MG

ROTTA, R. Desempenho térmico de edificações multifamiliares de interesse social em conjuntos habitacionais na cidade de Santa Maria - RS. 132 f. Dissertação (Mestrado) - Curso de Engenharia Civil, Centro de Tecnologia, Universidade Federal de Santa Maria, Santa Maria, 2009.

SANTOS, A. Paredes de concreto já dominam Minha Casa Minha Vida. 2016. Disponível em: http://www.cimentoitambe.com.br/paredes-de-concreto-minha-casa- minha-vida/. Acesso em: 11 dez. 2018.

SILVA, Arthur Santos et al. Incerteza do método de simulação da NBR 15575-1 para a avaliação do desempenho térmico de habitações. Ambient. constr., Porto Alegre, v. 14, n. 4, p. 103-117, Dec. 2014. DOI: http://dx.doi.org/10.1590/S1678-86212014000400008.

SOARES, M. M.; SILVA, A. C. S. B. Avaliação dos Parâmetros de Desempenho Térmico da NBR 15575 Para as Zonas Bioclimáticas 1, 2 e 3 Para Habitações Térreas de Interesse Social no Método Simplificado. In: ENCONTRO DE PÓSGRADUAÇÃO DA UNIVERSIDADE FEDERAL DE PELOTAS, 15, Pelotas, 2013. Anais [...]. Pelotas: UFP, 2013.

SORGATO, M. J. et al. Nota Técnica Referente à Avaliação Para a Norma de Desempenho NBR 15575 em Consulta Pública. Florianópolis: LABEEE, 2012.

SORGATO, M. J.; MELO, A. P.; LAMBERTS, R. Análise do Método de Simulação de Desempenho Térmico da Norma NBR 15575. In: ENCONTRO NACIONAL DE CONFORTO NO AMBIENTE CONSTRUÍDO, 12., 2013, Brasília. Anais [...]. Brasília: ANTAC, 2013.

ZANONI, V. A. G. Influência dos agentes climáticos de degradação no comportamento higrotérmico de fachadas em Brasília. 2015. 293 f. Tese (Doutorado em Arquitetura e Urbanismo) - Programa de Pós-Graduação da Faculdade de Arquitetura e Urbanismo da Universidade de Brasília, Brasília, 2015.

ZANONI, V; SANCHEZ, J.M.; BAUER, E. Estudo comparativo entre os dias típicos e a série 2001-2013 de dados horários climáticos. In: WORKSHOP DE TECNOLOGIA DE PROCESSOS E SISTEMAS CONSTRUTIVOS,1., 2017, Campinas. Anais [...]. Campinas: ANTAC-TECSIC, 2017.

\footnotetext{
${ }^{1}$ Roberta Bastos de Oliveira

Engenheira Civil. Mestranda em Estruturas e Construção Civil na Universidade de Brasília. Endereço postal: Universidade de Brasília, Programa de Pós-graduação em Estruturas e Construção Civil, Campus Darcy Ribeiro, Asa Norte, Brasília, DF Brasil. CEP 70.910-900

\section{${ }^{2}$ Camila dos Reis Alves}

Engenheira Civil. Mestre em Engenharia Civil pela Universidade Federal de Uberlândia. Endereço postal: Universidade Federal de Uberlândia, Programa de Pós-Graduação em Engenharia Civil, Campus Santa Mônica, Uberlândia, MG - Brasil. CEP 38.400-902
} 